\title{
Organizational Capital and Employment Fluctuations
}

\author{
Thijs van Rens* \\ CREI and Universitat Pompeu Fabra
}

November 2004

\begin{abstract}
In this paper I present a model in which production requires two types of labor inputs: regular productive tasks and organizational capital, which is accumulated by workers performing organizational tasks. By allocating more workers from organizational to productive tasks, firms can temporarily increase production without hiring. The availability of this intensive margin of labor adjustment, in combination with adjustment costs along the extensive margin (search frictions, firing costs, training costs), makes it optimal to delay employment adjustments. Simulations indicate that this mechanism is quantitatively important even if only a small fraction of workers perform organizational tasks, and explains why the hiring rate is persistent and why employment is slow to recover after the end of a recession.
\end{abstract}

JEL classification: D92 E24 J41 J64

Keywords: business cycles, labor market, organizational capital, jobless recoveries

*This paper is the last chapter of my dissertation at Princeton University. I am indebted to Robert Shimer for his advice and countless suggestions. I am also grateful to Vasco Curdia, Per Krusell, Guido Lorenzoni, Chris Sims, Coen Teulings, Antonella Tutino, and particularly to Sebastian Ludmer, Jonathan Parker, Giorgio Primiceri and Lawrence Uren as well as seminar participants at the Princeton macroeconomics seminar and various student seminars, the University of Chicago capital theory reading group and the Tinbergen Institute Amsterdam for many helpful discussions and comments. All remaining errors are mine. 


\section{Introduction}

Employment is strongly procyclical, but lags output by one to two quarters over the business cycle. This fact has received relatively little attention in the academic literature, but has recently been important in the policy debate. In the booms after the 1991 and 2001 recessions, which have become known as 'jobless recoveries', it took 14 and 29 months respectively for employment to return to the level it was at the end of the recession. ${ }^{1}$ This paper addresses the question why employment is slow to recover after a recession by providing an explanation for why it may not be optimal for firms to start hiring immediately after an increase in productivity.

I present a model of labor demand, in which production requires the input of two types of tasks. Of all employed workers, most but not all work on activities directly related to current production, say the assembly line. The remaining workers perform other duties, which I label organizational tasks: oiling the machines, bookkeeping, quality control or cleaning up the factory hall. Organizational tasks do not directly influence production but increase the stock of organizational capital, which enters in the production function.

Firms can use organizational capital to 'store' labor, which provides them with an intensive margin of labor adjustment. In combination with adjustment costs along the extensive margin (search frictions, firing costs, training costs), the availability of an intensive margin of adjustment makes it optimal to delay employment adjustments. Suppose that the number of employees in a firm is initially at its desired level when productivity increases. Because the marginal product of an extra worker has gone up, firms would like to increase production by employing more workers to take full advantage of the increase in productivity. But because there are costs associated with hiring more workers, firms may use the intensive margin of adjustment instead. By allocating more workers from organizational tasks to productive activities (making the mechanic, bookkeeper, assistant manager and janitor help out on the assembly line), firms can temporarily increase production without hiring extra workers. But after a while the fact that there is too little time to perform organizational tasks starts to hurt production (the machines are no longer lubricated, no new supplies have been ordered and the factory hall becomes a mess). Even if initially it was not optimal to pay the adjustment costs and hire extra workers, it may eventually become optimal to do so.

This story depends on three important ingredients of the model. First, firms have an incentive to postpone employment adjustments. Adjustment costs in combination with discounting provide this incentive: by postponing the adjustment costs, these costs are lower from today's perspective. ${ }^{2}$ Second, there is an alternative margin of labor adjustment available. This margin is provided by organizational capital which enters in the production function and is substitutable for regular labor input. Third, using the intensive margin of adjustment is initially costless but eventually costly. This property is driven by two assumptions: reallocating workers within the firm is costless, and organizational tasks do not enter directly in the production function but not performing

\footnotetext{
${ }^{1}$ All employees in the private sector, BLS Current Employment Statistics (establishment survey).

${ }^{2}$ If there is uncertainty about future productivity shocks, the 'option value of waiting' provides a second reason to postpone the adjustment costs. Uncertainty strengthens, but is not crucial for the results.
} 
these tasks gradually depletes the organizational capital stock.

The idea that organization is important for production has been used to explain a range of phenomena in macroeconomics: the common growth rate across firms of different sizes (Prescott and Visscher 1980), the large decline in output in transition economies (Blanchard and Kremer 1997) and the increase in the discrepancy between the stock market value of firms and the value of their installed capital (Hall 2000a). Brynjolfsson, Hitt and Yang (2002) present evidence that production, in addition to capital and labor, depends on intangible assets like skills, organizational structures and culture. They also find that investments in these intangible assets are often large and provide benefits over very long horizons. All of these papers focus on complementaries between organizational capital and physical capital or labor. But if organizational capital enters in a standard production function, it is not only complementary to but to some degree also substitutable for other inputs. In this paper I focus on substitution between organizational capital and labor.

Organization requires labor input: infrequent productive activities other than those directly related to current production. Examples are machine maintenance and employee training. In law firms, in busy times every hour worked is charged to a particular client but when there is not much work lawyers write hours as 'non-billable'. Another example is a screening task as in Prescott and Visscher (1980) that firms use to learn in what type of tasks a worker is most productive in order to optimally organize the production process.

Because organizational tasks generate lasting benefits, these tasks can be postponed when the productivity of current production is relatively high. Faced with temporarily high productivity or product demand, hiring more workers may therefore not be the only or even the first thing a firm does. Instead, it may postpone the replacement of an old machine, cancel a training session for its employees, or ask its workers to work longer hours for a few months. Conversely, a period of relatively low productivity is a good time to catch up with all of these things or to complete a reorganization of the production line rather than an immediate reason to let go some employees. One component of the intensive margin of adjustment are hours worked per employee. ${ }^{3}$ Contrary to employment, hours per worker do not lag but lead output, providing some evidence that firms indeed use the intensive margin before using the extensive margin of adjustment.

If adjustment costs in employment are non-convex, as in Bentolila and Bertola (1990) or Caballero, Engel and Haltiwanger (1997), it is optimal for firms not to respond to small shocks in the desired labor force, but to 'hoard' labor so long as the actual number of workers does not deviate too much from the desired level. Thus, the firm prevents making irreversible adjustments in case the shock is reversed. In response to a large shock (or a sequence of small shocks) workers are hired or fired to keep the difference between actual and desired employment within certain bounds. In the model with organizational capital, this type of adjustment costs may make it optimal to postpone rather than forego employment adjustments. Firms face a trade-off between postponing the adjustment costs and postponing employment adjustment. The gains from adjusting employment are initially small because the firm can absorb part of the shock by real-

\footnotetext{
${ }^{3}$ In fact, hours per worker are often referred to as the intensive margin, e.g. King and Rebelo (1999). Here I think of sending workers home early so that they get rested as one of several infrequent tasks that contribute to the organizational capital stock in the firm.
} 
locating workers within the firm, focusing on tasks directly related to production and postponing organizational tasks. But these gains increase as workers spend less time doing organizational tasks which leads to a reduction in their productivity in the long run.

Unlike in most models with non-convex adjustment costs, the gist of this result carries over to the case when adjustment costs are convex. With convex adjustment costs small adjustments are not irreversible and there is no reason to postpone employment adjustments. There is however, an incentive to adjust employment slowly because large adjustments quickly grow very costly. Because slow adjustments are basically costless, in the long run the model with convex adjustment costs reaches the frictionless optimal allocation of labor. But in the short run, if the adjustment costs are sufficiently high the model behaves essentially as if employment is fixed. In response to an increase in productivity, firms use the intensive margin of adjustment. As the stock of organizational capital is gradually depleted, the need to hire more workers becomes more urgent and hiring increases. The higher urgency justifies the higher adjustment costs necessary to adjust employment at a faster rate. Eventually, after a period of hiring has increased the employment level enough that the need for more workers becomes less urgent again, hiring falls back to zero. But because hiring is initially increasing, it reaches its highest level a while after productivity increased.

These dynamics are very different from those of standard models with convex adjustment costs. In a model with convex adjustment costs but no organizational capital, hiring jumps to its highest level immediately following an increase in productivity. In the organizational capital model this effect is counteracted by another effect. Immediately after the shock, the intensive margin of adjustment is still available and only when that margin gets exhausted does the need for hiring reach its peak. Depending on the model parameters, the combination of the two effects can deliver a monotonically decreasing impulse response for hiring like in the standard model or a hump-shaped response. The model behaves as if there were adjustment costs not in employment but in the hiring rate.

To explore the quantitative relevance of this mechanism, I extend the simple model to a full dynamic stochastic general equilibrium model. I then simulate this model and compare its predictions to a standard real business cycle model. The main problems in the real business cycle literature are that the model does not generate enough amplification and propagation of productivity shocks (King and Rebelo 1999). One way to understand these problems is that in the standard model there is only one channel to substitute consumption for leisure in times of low productivity: intertemporal substitution through the capital accumulation decision. This poses strong restrictions on the joint movement of employment, consumption and output (Hall 1997, 1999). Several papers have modified the basic model to address these problems. Extending the model with an alternative use of time that workers can substitute for market labor, like home production (Benhabib, Rogerson and Wright 1991) or job search (Hall 1995), helps to build in more amplification. Adjustment costs in employment help to build more propagation into the model (Cogley and Nason 1995).

In this paper I show that a combination of organizational capital and adjustment costs not only improves the model along those dimensions, but also provides an explanation why employment lags output over the business cycle and generates impulse 
responses that are consistent with evidence on persistence in the employment growth. Organizational capital provides a way for firms to substitute current productive tasks for organizational activities when productivity is relatively low. And because organizational capital is accumulable, the production function is non-time-separable in organizational labor, which gives rise to persistence in the hiring rate. In that sense the role of organizational capital is very similar to a model with nonseparable preferences over leisure (Kydland and Prescott 1982, Hall 1991). The difference is that the effect of organizational capital works on the demand side of the labor market and not through general equilibrium wage fluctuations. The model in this paper is also related to Hall's (2000b) model of recessions as reorganizations, which considers reorganization along the extensive margin (workers quitting to find a better job).

A third way to introduce nonseparabilities in production is a signal extraction framework in which firms are uncertain about whether the recession has ended. Demers (1991) analyzes a model with uncertainty about the state of demand, in which a firm updates its beliefs as information becomes available over time, in combination with irreversibility of investments in physical capital. He finds that this leads to gradual adjustment of the capital stock similar to convex adjustment costs in investment. In the context of a search model, Pries (2002) shows that if workers and firms are uncertain about the quality of their match, the hazard rate for match destruction decreases over time as production realizations reveal information about the match quality. Formalizing Hall's (1995) idea that recessions are followed by prolonged periods of increased job loss, Pries shows that learning about match quality implies that the unemployment rate remains high for a long time after a sharp negative shock to employment. The difference between these explanations and the one in this paper is that the organizational capital model does not depend crucially on uncertainty. Delays in adjustment predicted by the model with organizational capital are forecastable and are optimal even in a deterministic environment.

The next section lays out the basic model, which I keep as simple as possible in order to focus on the impact of organizational capital. In that section I also solve for the optimal allocation of labor between tasks in the absence of adjustment costs. Sections 3 and 4 present the analytical results for this model with non-convex and convex adjustment costs in employment respectively. I then turn to the quantitative importance of organizational capital for employment fluctuations. In section 5, I present a dynamic stochastic general equilibrium model with organizational capital and discuss how well it matches stylized facts about fluctuations in aggregate employment over the business cycle. I show that this model can replicate the persistence in employment and the autocorrelation pattern between employment and output better than a standard real business cycle model and slightly better than a model with convex adjustment costs in employment. Section 6 looks at impulse response functions and shows that the persistence in employment in the organizational capital model is generated by persistence in employment growth. The response of hiring is quite different from a model with only adjustment costs in employment and consistent with evidence on persistence in the worker flows and the hiring rate. The response of employment ressembles a jobless recovery. Section 7 summarizes the conclusions. 


\section{A simple model with organizational capital}

I consider the profit maximization decision of a representative firm that employs a fraction $N$ of the workers in the economy, taking the wage $w$ as given. Business cycles are driven by unanticipated and permanent changes in productivity, which are the only source of shocks in the economy. Only the production technology is non-standard because organizational capital enters into the production function. The partial equilibrium model described in this section is the simplest possible setup, which I use to illustrate the main results of the paper in sections 3 and 4 .

\subsection{Production technology}

Production requires the input of two types of tasks. Of the total number of $N$ employed workers, a fraction $h$ works on activities directly related to current production, say the assembly line. The remaining workers perform organizational tasks, which increase the stock of organizational capital. Production depends both on current labor input $h N$ and on the organizational capital stock $L$. For simplicity, the production function is assumed to be additively separable and to have the same degree of diminishing returns in both inputs, ${ }^{4}$

$$
Y=P f(h N)+f(L)
$$

where $Y$ is production of the consumption good and $P$ is the productivity of current productive activities relative to organizational capital. Because there is no physical capital in the model, I assume that $f($.$) is strictly increasing with decreasing returns to$ scale, $f^{\prime}>0$ and $f^{\prime \prime}<0$, so that there are diminishing returns in total effective labor input.

With a fraction $h$ of all employed workers allocated to current production, there are $(1-h) N$ workers available for organizational tasks. Organizational tasks do not enter directly in the production function, but production depends on the stock of organizational capital $L$, which is accumulated by workers performing organizational tasks by the following the law of motion.

$$
\dot{L}=\delta[(1-h) N-L]
$$

where $\delta>0$ is the depreciation rate of organizational capital. In specification (2), $L$ converges to $(1-h) N$ in the long run if the number of workers assigned to organizational tasks is constant. But if this number changes to a permanently higher or lower level, $L$ moves to this new level only gradually.

The depreciation parameter $\delta$ measures how often organizational tasks have to be performed to keep the organizational capital stock at a constant level. A higher value for $\delta$ makes the effect of organizational activities wear off faster, and makes organizational capital more similar to regular labor input. For $\delta \rightarrow \infty$ the formulation nests the case where there are two types of tasks required for production, but both are directly related to current production, i.e. $L=(1-h) N$, in which case the production function is time-separable.

\footnotetext{
${ }^{4}$ The second assumption is inconsequential, see section 3.4 .
} 


\subsection{Adjustment technology}

In response to a change in $P$, firms may want to change the allocation of workers between current productive and organizational activities, as well as the overall level of employment in the firm. Reallocating workers to different tasks within the firm is costless, but there are costs associated with adjusting the total number of employees. I denote these costs by a cost function $\phi(d N)$, with $\phi(0)=0$, which firms have to pay out of their revenues.

In section 3, I consider fixed adjustment costs of the form $\phi(d N)=\phi>0$ if $d N>0$ or $d N<0$ and $\phi(d N)=0$ only if $d N=0$. This cost function (just like proportional adjustment costs or any combination of fixed and proportional costs) is non-convex in zero and therefore displays irreversibility in the sense that the adjustment costs cannot be recovered by reversing the adjustment. In sections 4 and 5, the cost function is of the form $\phi(n)=\frac{1}{2} \phi n^{2}$ where $d N=n d t$. Because this function is convex in zero, infinitesimally small adjustments in employment are costless and therefore reversible.

For convenience, I assume that the adjustment costs are costs associated with changing the number of employees in the firm, not hiring and firing costs. The difference is that I assume it is costless to fire a worker and replace her with another. Because of this assumption the labor market is perfectly competitive even with non-convex adjustment costs. In the presence of non-convex hiring or firing costs, a worker would have bargaining power after she is hired.

\subsection{Profit maximization}

Profit maximization is not a static problem because the production function depends on organizational capital and is therefore not time-separable. The representative firm chooses a path of employment adjustments $d N$ and the fraction of workers assigned to current production $h$ to maximize the net present value its profits, taking the wage $w$ as given.

$$
V(L, N ; P)=\max _{h, d N} \int_{0}^{\infty} e^{-r t}[Y-N w-\phi(d N)] d t
$$

where $Y$ is aggregate production as in $(1), \phi(d N)$ are the adjustment costs in employment and $r$ is the interest rate, subject to the law of motion for organizational capital (2) and the constraints $0<h<1$ and $0<N<1$.

\subsection{Frictionless optimum}

As a benchmark, it is useful to solve the firm's profit maximization problem when adjustment costs are zero. Without adjustment costs, firms can set employment to its

desired level at every point in time and $N$ is a choice variable in addition to $h$. Value function (3) satisfies the Bellman equation,

$$
r V^{*}(L ; P)=\max _{h, N}\left\{\operatorname{Pf}(h N)+f(L)-N w+\delta[(1-h) N-L] V_{L}^{*}\right\}
$$

where $V^{*}$ denotes the value of the firm in the frictionless case and $V_{L}^{*}$ is the derivative of that value function with respect to the state variable $L$ or the shadowprice of a higher organizational capital stock. 
The first order conditions for $h$ and $N$, state that the marginal product of one extra worker in current productive tasks equals $\delta$ times the shadowprice of organizational capital, and both are equal to the wage.

$$
P f^{\prime}\left(h^{*} N^{*}\right)=\delta V_{L}^{*}=w
$$

The shadowprice of organizational capital is multiplied by $\delta$ because allocating an extra worker to organizational tasks increases the stock of organizational capital only by $\delta$, see (2). Because, by (5), $V_{L}^{*}$ is constant over time, the envelope condition for $L$ also reduces to a static relation.

$$
\frac{\delta}{r+\delta} f^{\prime}\left(L^{*}\right)=\delta V_{L}^{*}=w
$$

The marginal product of an extra worker in organizational tasks also equals the wage (and the marginal product of that worker in current productive activities). The marginal product of one extra unit of organizational capital $f^{\prime}(L)$ is multiplied by a factor $\delta /(r+\delta)$ because one extra worker increases $L$ only by $\delta$ but this higher $L$ then lasts forever. The infinite stream of higher production because of the increase in $L$ is discounted at rate $r+\delta$ because the organizational capital stock depreciates at rate $\delta$.

In the frictionless optimum the marginal products of an extra worker in current productive activities and in organizational tasks are equal to each other and equal to the wage at all times, and employment $N^{*}$ as well as the fraction of workers allocated to productive tasks $h^{*}$ are constant over time. Without adjustment costs, the solution to the dynamic profit maximization problem (3) is the statically optimal allocation. The desired number of workers allocated to current productive tasks is increasing in productivity $P$, but because the production function is additively separable, the optimal level of organizational capital does not depend on $P$.

\section{$3 \quad$ Fixed adjustment costs}

Now suppose that there are fixed adjustment costs $\phi$ associated with changing the number of employed workers $N$. At every point in time firms have to decide whether or not to adjust employment. If they do, they pay the adjustment costs $\phi$. Whether or not they adjust the number of employees, firms can always costlessly adjust labor along the intensive margin and allocate more or less workers to current productive tasks. This recursive formulation of profit maximization problem (3) is summarized by the Bellman equation.

$$
\begin{aligned}
r V(L, N ; P)=\max & \left\langle\max _{N^{\prime}} r\left[V\left(L, N^{\prime} ; P\right)-\phi\right],\right. \\
& \left.\max _{h}\left\{P f(h N)+f(L)-N w+\delta[(1-h) N-L] V_{L}\right\}\right\rangle
\end{aligned}
$$

where $V_{L}$ is the derivative of the value function with respect to $L$ or the shadowprice of organizational capital.

Suppose the economy initially is in steady state, when there is an increase in productivity $P$. I will show that for a range of values for the adjustment costs, the optimal 
policy involves employment adjustment after a delay. The proof runs by contradiction. Suppose that delayed adjustment is not optimal. Then, the optimal policy must be either to immediately hire some more workers or to never do so. In sections 3.1 and 3.2, I solve for the net present value of profits under each of these policies, which I denote by $V_{I A}$ and $V_{N A}$ respectively. In section 3.3, I then show that for some values of $\phi$ there is a feasible adjustment strategy involving delayed adjustment that gives a higher net present value of profits, denoted by $V_{D A}$, than never adjusting employment, $V_{D A}-\phi>V_{N A}$ at time $t \rightarrow \infty$, whereas for the same values of $\phi$ never adjusting employment gives higher profits than immediately adjusting employment, $V_{N A}>V_{I A}-\phi$ at time $t=0$. Therefore, neither of the two possible strategies without delay was optimal and it must be that the optimal policy involves delay. Another way to say this is that for some values for $\phi$ it is eventually optimal to adjust employment, but initially it is not.

\subsection{No employment adjustment}

If firms decide not to adjust employment $N$, the Bellman equation (7) reduces to

$$
r V(L ; N, P)=\max _{h}\left\{\operatorname{Pf}(h N)+f(L)-N w+\delta[(1-h) N-L] V_{L}\right\}
$$

In this case the first order condition for $h$, which prescribes that the marginal product of one extra worker in doing current productive tasks equals $\delta$ times the shadowprice of organizational capital, can be combined with the envelope condition (or co-state equation) for $L$ to get an Euler equation for the fraction of workers assigned to current productive tasks $h$.

$$
\frac{h N f^{\prime \prime}(h N)}{f^{\prime}(h N)} \frac{\dot{h}}{h}=r+\delta-\delta \frac{f^{\prime}(L)}{P f^{\prime}(h N)}
$$

In combination with the law of motion for $L(2)$, the Euler equation forms a system of two differential equations in $h(t)$ and $L(t)$. The system admits a unique steady state and is saddle path stable. ${ }^{5}$ Therefore, there is a unique path for $h$ and $L$ that satisfies the first order conditions, an initial condition for the state variable $L$ and a transversality condition. This solution takes the usual form that $h$ immediately jumps when $P$ changes, after which $h$ and $L$ converge to their steady state values.

The steady state solution is given by $\bar{L}=(1-\bar{h}) N$ and

$$
P f^{\prime}(\bar{h} N)=\frac{\delta}{r+\delta} f^{\prime}((1-\bar{h}) N)
$$

When $P$ increases, in the long run the number of worker in current productive activities $\bar{h} N$ has to increase and/or the number of workers in organizational tasks $(1-\bar{h}) N$ has to decrease to equalize the marginal product of a worker in each type of task. Because the total number of employed workers $N$ is fixed, it must be that the fraction of workers assigned to current production $\bar{h}$ is increased. Notice that if the production function is

\footnotetext{
${ }^{5}$ That the steady state exists and is unique can be seen from (10) with $f($.$) strictly concave. Local$ saddle path stability is shown by linearizing the system around the steady state and calculating the eigenvalues of the linearized system. Global saddle path stability follows because the $\dot{L}=0$ curve is strictly decreasing and the $\dot{h}=0$ curve is strictly increasing because $f($.$) is strictly concave.$
} 


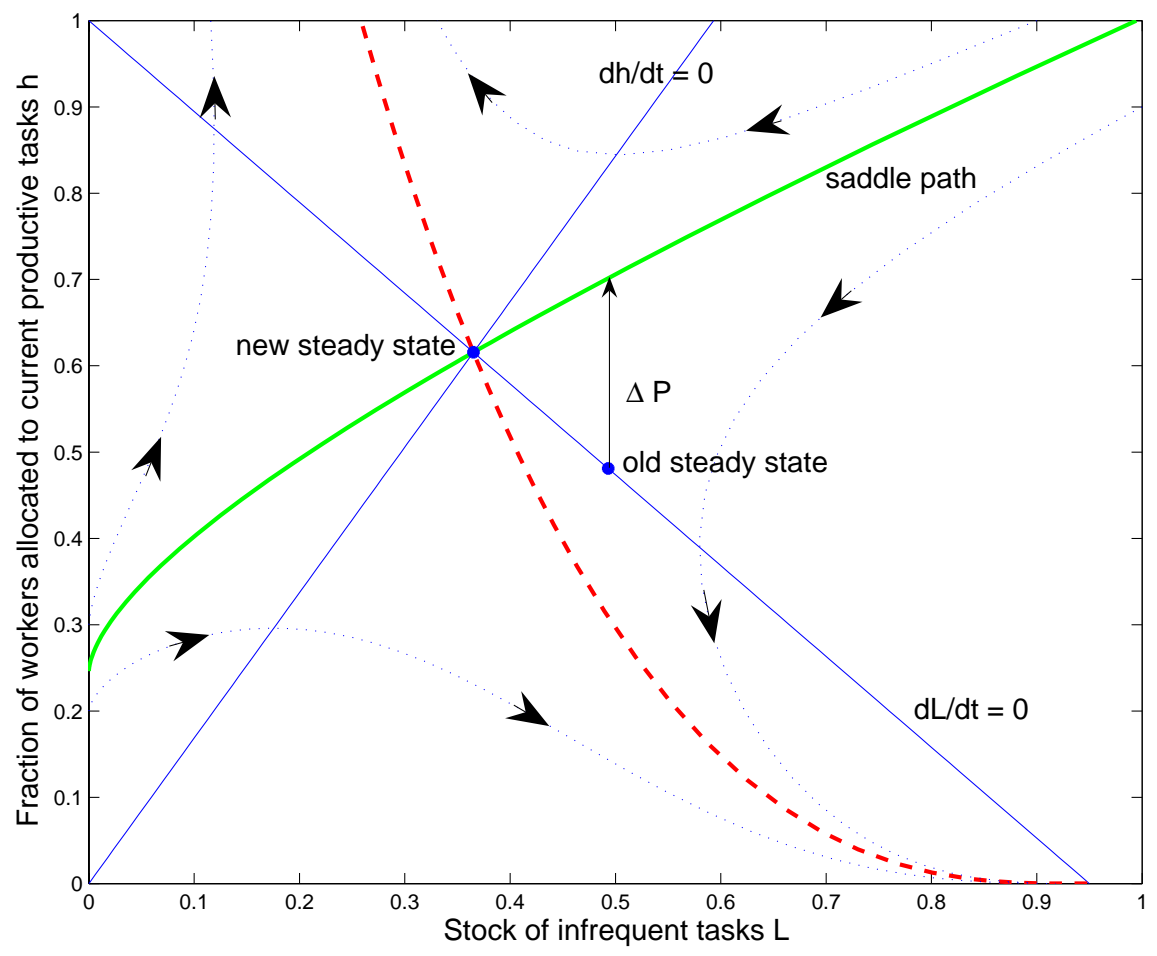

Figure 1: Phase diagram for the dynamics of $L$ and $h$ for fixed $N$. Parameters: $\alpha=1 / 3$, $r=4 \%$ per annum, $\delta=24 \%$ per annum.

of the Cobb-Douglas form, then $N$ drops out of condition (10) and the $h$ that satisfies this equation is the same that satisfies conditions (5) and (6), so that $\bar{h}=h^{*}$.

An increase in $P$ raises the marginal product of an extra worker in current production, making it higher than the marginal product of an extra worker in organizational tasks and higher than the wage. By reallocating some workers from organizational tasks to productive activities, firms increase production and reduce the organizational capital stock, thus reducing the productivity of the marginal worker in productive tasks and increasing the productivity of organizational capital until these are equal again. Firms would also like to equalize the marginal product of labor to the wage, but without hiring more workers that is impossible. By reallocating workers within the firm, the gap between the marginal product of an extra worker in production and the wage is reduced, though not to zero. The intensive margin is distorted (the marginal product of an extra worker in organizational tasks now also exceeds the wage) and absorbs part of the distortion along the extensive margin. Firms cannot equate the marginal product of labor to the wage because they have only one instrument (the allocation of workers within the firm $h$ ) with which to minimize the overall distortion along two margins.

Now consider the transition dynamics in response to an increase in productivity $P$. Because in steady state the fraction of workers assigned to current productive activities increases, the steady state level of the organizational capital stock $\bar{L}$ goes down. Thus, in response to the increase in $P$ organizational capital declines. But since it can do so only gradually, during the transition $L$ is greater than its new steady state level, so that the marginal product of organizational capital is smaller than in steady state. By the Euler equation (9) that implies that $\dot{h}<0$, the fraction of workers allocated to 
direct productive activities gradually decreases (notice that the left-hand side of (9) is negative because $\left.f^{\prime \prime}<0\right)$. Therefore, $h$ must have initially jumped up overshooting its new higher steady state level. This is illustrated in figure 1 . The intuition is that it is optimal to allocate a few more workers from organizational tasks to production, which in the long run will lead to a lower stock of organizational capital. But in the short run the stock of organizational capital is still at its old higher level. Firms take advantage of that by taking even more workers away from organizational tasks, running down the organizational capital stock faster in order to bring forward higher production. As the excess stock of organizational capital gets depleted, some workers are reallocated back from current production to organizational tasks.

The net present value of profits conditional on never adjusting employment, is obtained by substituting the adjustment policy into value function (3).

$$
V_{N A}(L ; N, P)=\int_{0}^{\infty} e^{-r t}\left[\operatorname{Pf}\left(h_{N A} N\right)+f\left(L_{N A}\right)-N w\right] d t
$$

where $h_{N A}(t)$ and $L_{N A}(t)$ follow the dynamics described here and their steady state levels $\bar{h}_{N A}=h^{*}$ and $\bar{L}_{N A}$ satisfy $(10)$ and $\bar{L}_{N A}=\left(1-h^{*}\right) N$.

The value of the program $V_{N A}(L(t) ; N, P)$ decreases over time because the organizational capital stock $L$ is gradually run down. Profits are highest in the beginning because $h_{N A}$ and $L_{N A}$ and therefore production are at their highest levels immediately after the increase in productivity and then decrease.

\subsection{Immediate employment adjustment}

If employment is adjusted immediately after the increase in productivity, it is set to maximize the value of the program henceforward. Because after the initial adjustment, employment remains constant, the value of the program is given by (11) for given $N$. Thus, the value if employment is immediately adjusted is given by

$$
V_{I A}(L ; P)=\max _{N} V_{N A}(L ; N, P)
$$

Because the optimal amount of hiring will depend on the initial value of the organizational capital stock, in general it is hard to solve for $V_{I A}$.

The problem simplifies considerably if the economy was initially in the frictionless optimum $L=L^{*}$. In response to an increase in productivity $P$, in the absence of adjustment costs, by (5) it is optimal to increase labor input in current productive activities $h N$. However, from (6) the optimal level of the stock of organizational capital $L$ and therefore by law of motion (2) also the optimal labor input in organizational tasks $(1-h) N$ are not affected by the increase in $P$. If there were no adjustment costs, firms would hire extra workers and assign all of them to current productive activities, keeping the number of workers performing organizational tasks constant. And if the economy was in steady state before the increase in $P$, then $h N$ and $L$ are immediately at their optimal levels after the increase in productivity as well so that there are no dynamics beyond the initial adjustments in $h$ and $N$. A single burst of hiring immediately takes

the economy to its new steady state level. But that adjustment policy is also feasible if employment is adjusted once immediately after the change in productivity. Therefore, 


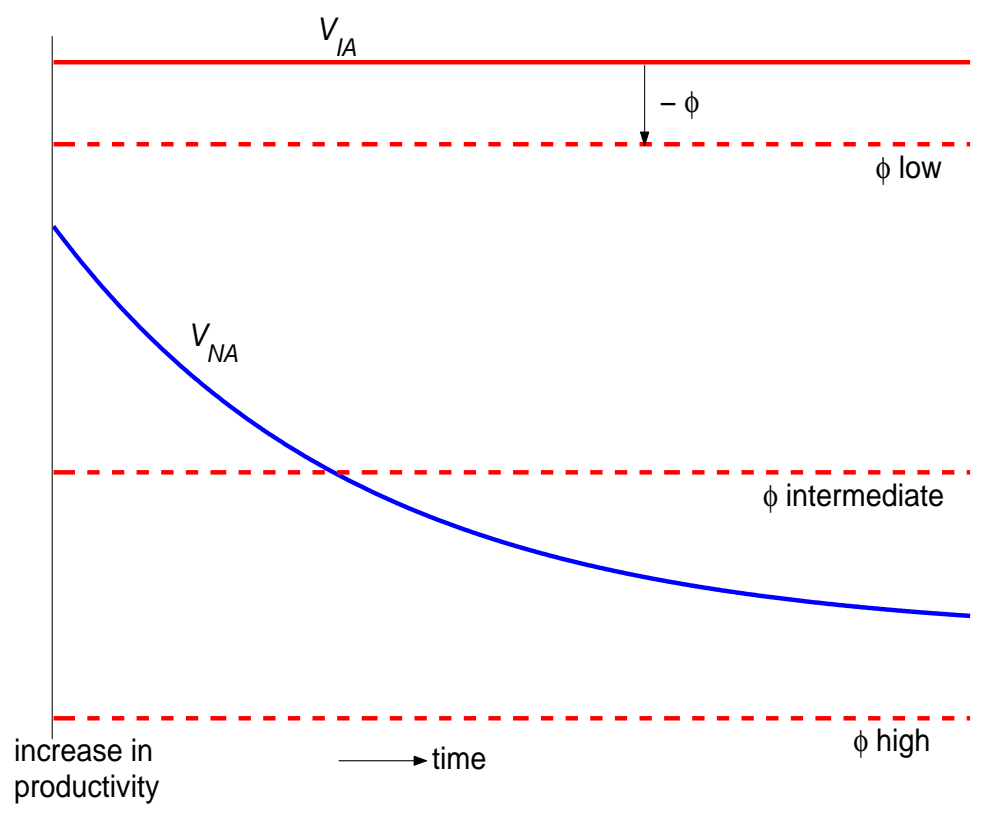

Figure 2: Net present value of profits over time if both employment and the allocation of workers within the firm are adjusted $V_{I A}$ compared to the net present value of profits if only the intensive margin is adjusted $V_{N A}$.

the value of the program in this case equals the value of the firm in the frictionless model if the economy was initially in steady state. Unlike in the case where employment is not adjusted, firms have two instruments to adjust labor input, $h$ and $N$, and they can equalize the marginal product of an extra worker both in current productive activities $f^{\prime}(h N)$ and in organizational tasks $f^{\prime}(L)$ to the wage.

Because there are no dynamics beyond the initial adjustments in $h$ and $N$, profits are constant over time and the value of the program is just the annuity value of an infinite stream of constant profits.

$$
V_{I A}\left(L^{*} ; P\right)=V^{*}\left(L^{*} ; P\right)=\frac{1}{r}\left[P f\left(h^{*} N^{*}\right)+f\left(L^{*}\right)-N^{*} w\right]
$$

where $h^{*}, N^{*}$ and $L^{*}$ satisfy conditions (5) and (6) with $L^{*}=\left(1-h^{*}\right) N^{*}$.

\subsection{Delayed adjustment}

Now consider the decision whether or not to hire extra workers. If a firm decides to hire more workers, it will do so optimally and the net present value of its profits in that case is given by (13). If it decides not to adjust employment, it will still set $h$ optimally and its value is given by (11). Because $N$ is set optimally, the value of the firm after employment has been adjusted must by higher than if it is not, see (12). The question is whether the difference in value is sufficient to merit paying the adjustment costs $\phi$. This is illustrated in figure 2. As argued in section 3.1, the value of the program in the case when employment is not adjusted decreases over time. 
The picture shows three different cases. If the adjustment costs are very low (relative to the size of the change in productivity), net profits when workers are hired are always higher than profits if employment is not adjusted. In this case, the increase in the value of the firm from adjusting employment is always worth paying the adjustment costs, and as soon as productivity increases firms will decide to hire more workers. The second case is when adjustment costs are very high. In this case the increased value of the program by hiring more workers is not worth paying the adjustment costs, and firms will never adjust employment.

The middle case is the more interesting one. For intermediate values of the adjustment costs, profits are initially higher if a firm decides not to adjust employment, but after a while that may reverse because profits are decreasing. If a firm decides not to adjust employment when productivity changes, it will regret that choice at a later point in time. But this does not necessarily imply that it is optimal to postpone adjusting employment. Suppose a firm decides to hire more workers as soon profits become lower than net profits would have been if employment would have been adjusted immediately after the increase in $P$. At that point, profits do not stay at the same level, because the organizational capital stock is at a lower level than it would have been if these workers had been hired when the change in productivity occurred. Therefore, there are costs as well as benefits to postponing employment adjustment compared to adjusting immediately after a change in productivity.

By postponing to hire more workers, initially the value of the program is higher because no adjustment costs have to be paid. Of course production is lower than if employment would have been adjusted to its optimal level, but the net effect of postponing adjustment costs and postponing higher production is positive. The cost of delaying adjustment is that after employment is adjusted, $L$ is lower than it would have been if more workers had been hired immediately. To determine if the benefits outweigh the costs, I need to be specific about the adjustment policy if employment is adjusted after a delay. I will propose a feasible adjustment policy that involves delayed employment adjustment and show that it gives higher profits than both immediately adjusting and never adjusting employment. Then, the optimal policy must involve at least some delay in adjustment.

Proposition 1 In the organizational capital model with fixed costs $\phi$ of adjusting employment, there is a range of values for $\phi>0$ for which it is not optimal to adjust employment immediately after the change in productivity but it is optimal to do so eventually. Therefore, the optimal adjustment policy involves delayed employment adjustment.

Proof. Consider the following adjustment policy. When productivity increases, initially no new workers are hired and the fraction of workers assigned to current productive tasks is set to the level $h^{*}$ that is optimal in steady state. Then, after a very long time $T \rightarrow \infty$, new workers are hired, setting employment to the same levels that would have been optimal if these workers would have been hired immediately, maintaining the fraction of workers assigned to current production at $h^{*}$. If before the increase in productivity, employment is at level $N$, the proposed adjustment policy involving delay is given by

$$
\left[N_{D A}(t), h_{D A}(t)\right]= \begin{cases}{\left[N, h^{*}\right]} & \text { for } t<T \\ {\left[N^{*}, h^{*}\right]} & \text { for } t \geq T\end{cases}
$$


where $h^{*}$ and $N^{*}$ are given by (10) and (5). While not necessarily optimal, this policy is clearly feasible. I will show that for intermediate values of the adjustment costs $\phi$, this adjustment policy results in higher profits both than adjusting immediately and than never adjusting employment.

First, consider the program before employment is adjusted, $t<T$. With $h=h^{*}$ and $N<N^{*}$ constant, the organizational capital stock, which initially is at its frictionless optimum, is depleted exponentially by its law of motion (2).

$$
\dot{L}_{D A}=\delta\left[\left(1-h^{*}\right) N-L_{D A}\right]=\delta\left[\bar{L}_{N A}-L_{D A}\right]
$$

With initial condition $L_{D A}(0)=L^{*}$, this differential equation has a unique closed-form solution

$$
L_{D A}(t)=\bar{L}_{N A}+\left(L^{*}-\bar{L}_{N A}\right) e^{-\delta t} \text { for } 0 \leq t<T
$$

Because time $T$ is infinitely far away, the value of a firm under the delayed adjustment policy $V_{D A, t}$ at time $t=0$ equals the value of a firm that will never adjust employment. The net present value of future profits is obtained by substituting $h_{D A}(t)$ and $L_{D A}(t)$ into (3).

$$
V_{D A, t=0}\left(L^{*}, N ; P\right)=\frac{1}{r}\left[\operatorname{Pf}\left(h^{*} N\right)-N w\right]+\int_{0}^{\infty} e^{-r t} f\left(\bar{L}_{N A}+\left(L^{*}-\bar{L}_{N A}\right) e^{-\delta t}\right) d t
$$

Comparing this value to the value of the firm if employment is adjusted immediately after the change in productivity (13), adjusting immediately is not optimal if

$$
V_{I A}\left(L^{*} ; P\right)-V_{D A, t=0}\left(L^{*}, N ; P\right) \equiv \underline{\phi}<\phi
$$

Now, consider the program at date $T \rightarrow \infty$. By this time, the stock of organizational capital has been depleted to its steady state level $L_{D A}(T)=\bar{L}_{N A}$. Because for $t \geq T$, employment and the fraction of workers in current productive tasks are again constant and $N=N^{*}$ is now set to its frictionless optimum level, organizational capital is being built up again and exponentially moves towards $L^{*}=\left(1-h^{*}\right) N^{*}$.

$$
L_{D A}(t)=L^{*}+\left(\bar{L}_{N A}-L^{*}\right) e^{-\delta(t-T)} \text { for } t \geq T
$$

Substituting $h_{D A}(t)$ and $L_{D A}(t)$ into (3) gives the net present value of future profits at time $T$.

$$
V_{D A, t=T}\left(\bar{L}_{N A} ; P\right)=\frac{1}{r}\left[\operatorname{Pf}\left(h^{*} N^{*}\right)-N^{*} w\right]+\int_{0}^{\infty} e^{-r t} f\left(L^{*}+\left(\bar{L}_{N A}-L^{*}\right) e^{-\delta t}\right) d t
$$

If this value is greater than $V_{N A}\left(\bar{L}_{N A} ; N, P\right)$ as in (11), then at time $T$ it is optimal to adjust employment.

$$
V_{D A, t=T}\left(\bar{L}_{N A} ; P\right)-V_{N A}\left(\bar{L}_{N A} ; N, P\right) \equiv \bar{\phi}>\phi
$$

The set of values for the adjustment costs $\phi$ for which (16) and (18) are simultaneously satisfied is non-empty if $\underline{\phi}<\bar{\phi}$. Substituting (11), (13), (15) and (17) into (16) 
and (18), we get

$$
\begin{aligned}
\bar{\phi}-\underline{\phi}= & \int_{0}^{\infty} e^{-r t} f\left(L^{*}+\left(\bar{L}_{N A}-L^{*}\right) e^{-\delta t}\right) d t-\frac{1}{r} f\left(\bar{L}_{N A}\right) \\
& +\int_{0}^{\infty} e^{-r t} f\left(\bar{L}_{N A}+\left(L^{*}-\bar{L}_{N A}\right) e^{-\delta t}\right) d t-\frac{1}{r} f\left(L^{*}\right)
\end{aligned}
$$

Because the production function is strictly concave, by Jensen's inequality

$$
\begin{aligned}
\bar{\phi}-\underline{\phi}>\frac{1}{r} f\left(L^{*}\right)+\frac{1}{r+\delta}[ & \left.f\left(\bar{L}_{N A}\right)-f\left(L^{*}\right)\right]-\frac{1}{r} f\left(\bar{L}_{N A}\right) \\
& +\frac{1}{r} f\left(\bar{L}_{N A}\right)+\frac{1}{r+\delta}\left[f\left(L^{*}\right)-f\left(\bar{L}_{N A}\right)\right]-\frac{1}{r} f\left(L^{*}\right)=0
\end{aligned}
$$

Finally, again using concavity

$$
\begin{aligned}
\underline{\phi} & =\frac{1}{r}\left[\operatorname{Pf}\left(h^{*} N^{*}\right)-\operatorname{Pf}\left(h^{*} N\right)-\left(N^{*}-N\right) w\right] \\
& +\int_{0}^{\infty} e^{-r t}\left[f\left(L^{*}\right)-f\left(\bar{L}_{N A}+\left(L^{*}-\bar{L}_{N A}\right) e^{-\delta t}\right)\right] d t \\
& >\frac{1}{r}\left[\left(P f^{\prime}\left(h^{*} N^{*}\right) h^{*}-w\right)\left(N^{*}-N\right)+\frac{\delta}{\rho+\delta} f^{\prime}\left(L^{*}\right)\left(L^{*}-\bar{L}_{N A}\right)\right]
\end{aligned}
$$

and substituting the steady state conditions,

$$
\underline{\phi}>\frac{w}{r}\left[h^{*} N^{*}-h^{*} N-N^{*}+N+L^{*}-\bar{L}_{N A}\right]=0
$$

which completes the proof that there is a non-empty set of positive values for $\phi$ for which the optimal policy involves delayed adjustment.

The result that delayed adjustment is optimal for a range of values for the adjustment depends on three important ingredients of the model: concavity of the production function, the fact that organizational capital is gradually depleted if employment is not adjusted and discounting. Concavity is important because if the production function is linear, current productive tasks and organizational capital are perfect substitutes, in which case there is no interior optimum allocation of workers within the firm. Therefore, any positive organizational capital stock is used up immediately and $L$ equals zero in steady state, regardless of the value of $P$. With $L$ equal to zero, there is no intensive margin of adjustment available that can be used to respond to changes in productivity without adjusting employment.

The assumption that organizational capital is gradually depleted if employment is not adjusted in response to an increase in productivity implies that $\bar{L}_{N A}<L^{*}$ so that eventually the incentive to adjust employment is higher than initially. The more persistent is organizational capital, the wider is the range of values for the adjustment costs for which it is optimal to delay employment adjustments. To see this, consider a small shock to $P$ so that $\bar{L}_{N A}$ is close to $L^{*}$, and take second order Taylor approximations of the production function around the frictionless optimum to get an approximate expression for $\bar{\phi}-\phi$. Assuming a Cobb-Douglas production function with $\alpha \equiv-L^{*} f^{\prime \prime}\left(L^{*}\right) / f^{\prime}\left(L^{*}\right)>0$ and using (6) to substitute out for $L^{*}$, this expression can be written as

$$
\bar{\phi}-\underline{\phi} \simeq-\frac{\delta f^{\prime \prime}\left(L^{*}\right)}{(r+2 \delta)(r+\delta)}\left(\bar{L}_{N A}-L^{*}\right)^{2}=\frac{\alpha w}{r+2 \delta}\left(\frac{r+\delta}{\delta} w\right)^{1 / \alpha}\left(\bar{L}_{N A}-L^{*}\right)^{2}
$$


The factor $\left(\bar{L}_{N A}-L^{*}\right)^{2}$ measures the size of the change in $P$, which because of the quadratic approximation results in a potential increase in production from adjusting employment proportional to the square of the deviation of $L$ from its optimal level. A higher depreciation rate of organizational capital $\delta>0$ decreases the range of values for $\phi$ for which delayed adjustment is optimal, because it takes longer before the surplus of the organizational capital stock is depreciated, as measured by the effective discount rate $r+2 \delta$ for this surplus. The intuition is that with a lower $\delta$, organizational tasks are less similar to frequent tasks in production and the profit maximization is less similar to the standard static problem. In addition, a higher $\delta$ decreases the marginal product of organizational capital $(r+\delta) w / \delta$. If it was initially not optimal to adjust employment, a lower marginal production of organizational capital makes it less likely that the subsequent decrease in $L$ makes employment adjustment eventually optimal. ${ }^{6}$

Finally, discounting is crucial because it provides an incentive to postpone the adjustment costs. Consider a firm that wants to hire more workers, but is considering to delay this adjustment. The gain from postponing the adjustment costs is that the adjustment costs can be paid later. The costs from postponing the adjustment consists of two parts: production is lower than if employment is set to its optimal level, and over time production decreases even further as the organizational capital stock is run down. Since the second effect is second order, it is irrelevant when considering postponing the adjustment costs by a very short period of time. Postponing the first order increase in production generates costs equal to the difference in the flow profits times the period of delay. These costs are independent of the discount rate. The gain from adjusting the adjustment costs $\phi$ on the other hand, generates flow benefits $r \phi$ that are increasing in the discount rate. Therefore, if the discount rate is higher, it is more likely that delayed employment adjustment is preferred over immediate adjustment. Because a similar argument holds after $L$ gets depleted, it is less obvious that a higher discount rate increases the range of values for the adjustment costs that give rise to delayed adjustment. But for a Cobb-Douglas production function this is the case, see (20).

\subsection{Generalizations}

Clearly, the baseline model in sections 2 and 3 is very stylized. In this section I briefly discuss if and how the most important simplifying assumptions affect the result that it is optimal to delay employment adjustment.

\subsubsection{Production technology}

Production function (1) is restrictive for two reasons: it is additively separable and assumes the same degree of curvature (diminishing returns) in current productive tasks and organizational capital. It is straightforward to show that the latter simplifying assumption is not important. Allowing for a production function of the form $Y=$ $P f(h N)+g(L)$, the analysis in section 3 goes through unchanged if both $f($.$) and g($.

\footnotetext{
${ }^{6}$ Notice that $\bar{\phi}-\phi>0$ is a sufficient but not necessary condition for delayed adjustment and it is therefore not true that for all values of the adjustment costs above $\bar{\phi}$ it is optimal not to adjust and for all values below $\phi$ it is optimal to adjust immediately. But as $\bar{\phi}-\phi$ becomes arbitrarily large for arbitrarily small $\delta$, the range of values for the adjustment costs for which delayed adjustment is optimal must become arbitrarily large as well.
} 
are strictly concave. Additive separability however, is important to the result. In the more general production technology

$$
Y=A\left[(1-\beta)(P h N)^{\theta}+\beta L^{\theta}\right]^{\frac{1-\alpha}{\theta}}
$$

$\beta \in[0,1]$ is the share of organizational capital in total labor input and $\theta$ measures the degree to which regular productive tasks and organizational capital are substitutes. The elasticity of substitution between current productive tasks and organizational capital is $1 /(1-\theta) \in(0, \infty)$, where $\theta \rightarrow-\infty$ corresponds to an elasticity of substitution of 0 (perfect complements), $\theta=1$ corresponds to infinite elasticity of substitution (perfect substitutes) and $\theta \rightarrow 0$ corresponds to a Cobb-Douglas production function with an elasticity of substitution equal to one.

With this more general production technology, the model displays delayed adjustment if $\theta>0$. This restriction is necessary to guarantee that when productivity increases, more workers are assigned to current productive activities. The intuition is that changes in $P$ have two counteracting effects on the optimal fraction of workers $h$ that are assigned to current production. First, an increase in $P$ makes current productive tasks relatively more productive, increasing the optimal fraction of workers assigned to these tasks. But second, an increase in $P$ directly increases the input of productive activities $P h N$ into the production function. When each worker becomes more productive in performing these tasks, less workers are necessary to perform the same number of tasks. If there are strong complementarities between productive tasks and organizational capital, which is the case for $\theta<0$, the second effect dominates. The intuitive case is that regular productive tasks and organizational capital are sufficiently substitutable so that an increase in productivity shifts the allocation of workers from organizational tasks to production. In the case of a Cobb-Douglas production function (with $\theta=0$ or an elasticity of substitution of 1) the two effects exactly cancel out. Another way to see this is that with a Cobb-Douglas production function, a 'current production enhancing' technological change in $P$ is indistinguishable from a change in total factor productivity $A$. And because a change in total factor productivity affects the productivity of productive tasks and organizational capital equally, it does not change the optimal allocation of workers between the two types of tasks.

\subsubsection{Stochastic productivity}

The baseline model is deterministic in order to make the analysis more tractable. I analyzed changes in productivity as a comparative statics exercise, and these changes must be interpreted as unanticipated and permanent. Clearly therefore, the results in section 3 do not depend on the stochastic nature of productivity shocks. But from what we know about stochastic models with non-convex adjustment costs, stochastic productivity shocks may strengthen the results for two reasons. First, in a stochastic model the 'option value of waiting' provides another reason to discount the future apart from impatience. The probability that the productivity shock is reversed plays a role similar to the discount rate and makes delayed adjustment more likely to be optimal. Secondly, if shocks to productivity are transitory rather than permanent, they have a stronger effect on the relative productivity of productive versus organizational tasks. Because 
productive activities are frequent tasks, their productivity is immediately related to $P$. Organizational capital however, lasts for a period of time. If during this period the increase in productivity is reversed, then organizational tasks performed today become less productive. That diminishes the incentive to invest in organizational capital at times when productivity is high. Stronger mean reversion in the productivity shocks plays a similar role to a higher $\theta$ in (21), making it more likely that delayed adjustment is optimal.

\subsubsection{General equilibrium}

The model in this section is a partial equilibrium model: for a given wage $w$ all fluctuations in employment are driven by changes in labor demand. Alternatively, profit maximization problem (3) can be interpreted as the intertemporal utility maximization problem of a representative household that owns the firm and decides how many of its members to send to work in it while distributing all its output among its members for immediate consumption. That problem is equivalent if $(i)$ employed workers cannot choose how many hours they want to work, $(i i)$ the utility function is linear in consumption and (iii) the consumption good is non-storable. If workers cannot choose how many hours to work, then market clearing on the labor market requires that all workers are indifferent between working full-time or being unemployed so that the wage equals the reservation wage at all times. Linear utility and a non-storable consumption good imply that the household has neither an incentive nor an opportunity for consumption smoothing. While the first assumption is arguably realistic, the assumption that there is no saving clearly is not. However, the results for employment adjustment in this section go through in a more general model with a nondegenerate consumption choice. ${ }^{7}$

\section{Convex adjustment costs}

This section analyzes the simple organizational capital model when adjustment costs in employment are convex. With convex adjustment costs, employment adjustments are continuous and can be represented by a law of motion for employment,

$$
\dot{N}=n
$$

where $n$ is the amount of employment adjustment (hiring or firing) which is a control variable to the firm. The adjustment costs are $\phi(n)=\frac{1}{2} \phi n^{2}$ and the Bellman equation for profit maximization problem (3) subject to (2) and (22) is given by,

$$
\begin{aligned}
r V(L, N ; P)= & \max _{h, n}\left\{P f(h N)+f(L)-N w-\frac{1}{2} \phi n^{2}\right. \\
& \left.+\delta[(1-h) N-L] V_{L}+n V_{N}\right\}
\end{aligned}
$$

where $V_{N}$ is the partial derivative of the value function with respect to $N$ or the shadowprice of an extra employed worker.

Because employment adjustments are locally costless and reversible, there is no reason to postpone adjustments. Nevertheless the gist of the result in the previous section

\footnotetext{
${ }^{7}$ A note, in which I analyze the organizational capital model with fixed adjustment costs in general equilibrium, is available from my website at www.princeton.edu/ ${ }^{\sim}$ tvanrens.
} 
carries over to this case. I will show that in the model with convex adjustment costs it is optimal to 'delay' employment adjustments, in the sense that the largest adjustment takes place a while after a change in productivity. See the discussion of the simulated impulse responses in section 6.1 for a more detailed interpretation of this result.

\subsection{First order conditions}

Combining the first order and envelope conditions gives Euler equations for $h$ and $n$, which describe adjustments along the intensive and extensive margin. The Euler equation for $h$ is similar to its Euler equation if employment is not adjusted (9) but includes an additional term because the firm takes into account that also the extensive margin is being adjusted.

$$
\frac{\dot{h}}{h}=\frac{f^{\prime}(h N)}{h N f^{\prime \prime}(h N)}\left[r+\delta-\delta \frac{f^{\prime}(L)}{P f^{\prime}(h N)}\right]-\frac{n}{N}
$$

Employment adjustments $n$ satisfy a second Euler equation.

$$
\dot{n}=r n-\frac{P f^{\prime}(h N)-w}{\phi}
$$

The Euler equations for $h$ and $n$, combined with the laws of motion (2) and (22) for $L$ and $N$, form a system of four first-order ordinary differential equations in the four variables as functions of time.

In the long run the model with convex adjustment costs reaches the frictionless optimum, as can be seen by substituting $\dot{N}=n=0$ and $\dot{n}=0$ into (25) and $n=0$ and $\dot{h}=0$ into (24) and comparing to (5) and (6). But in the short run, if the adjustment costs $\phi$ are sufficiently high, hiring $n$ is close to zero and the model behaves essentially as if employment is fixed. Thus, in response to an increase in productivity, firms first use the intensive margin of adjustment. As the stock of organizational capital is gradually depleted, $h$ decreases again and by (25) hiring increases because the marginal product of an extra worker in current productive tasks exceeds the wage by more. An alternative way to understand this, is that firms set the speed at which they hire new workers in order to (approximately) equate the marginal adjustment costs to the marginal costs of not adjusting employment. ${ }^{8}$ When the organizational capital stock is depleted, workers are assigned back to doing organizational tasks which increases the marginal costs of not hiring more workers. Therefore, it becomes optimal to hire at a faster rate even though this increases the marginal adjustment costs. Eventually, as employment approaches its new optimum after a period of hiring, the hiring rate falls back to zero as the marginal product of an extra worker approaches $w$ again.

\footnotetext{
${ }^{8}$ If $\phi$ is sufficiently high then $N$ is approximately constant and $n \simeq 0$, so that the allocation of workers within the firm $h$ moves according to (9). Then, the Euler equation for hiring (25) is decoupled from the rest of the system and its only solution that satisfies transversality is $\dot{n}=0$ so that $r n=$ $\left(P f^{\prime}(h N)-w\right) / \phi$ or $\phi n=\left(P f^{\prime}(h N)-w\right) / r$. The left-hand side of this expression are the marginal adjustment costs, the right-hand side is the annuity value of the marginal costs from not adjusting employment.
} 


\subsection{Persistence in hiring}

In a model with convex adjustment costs in employment but no organizational capital, we expect hiring to jump up to its highest level immediately after the increase in productivity. But in the organizational capital model with convex adjustment costs, hiring may continue to increase after its initial jump. Therefore employment adjustment is delayed in the sense that the largest amount of hiring occurs not immediately after the increase but a while later. I derive a parameter condition under which $\dot{n}>0$ immediately after an increase in productivity.

Euler equation (25) can be used to calculate $\dot{n}$ given the initial values for $h$ and $n$ immediately after the shock. The transversality condition prescribes that in the profit maximizing allocation $h$ and $n$ have to be on the stable manifold for every $L$ and $N$. This provides two boundary conditions which in combination with initial conditions for $L$ and $N$ determine a unique solution to the system of differential equations. There is no closed-form solution for the stable manifold (the policy rules) in the nonlinear model. ${ }^{9}$ Therefore I linearize the system around its steady state. For small shocks to productivity, the stable hyperplane of the linearized system is a good approximation of the nonlinear stable manifold because with a convex adjustment cost function, (3) is a well-defined concave dynamic programming problem with an interior solution. Numerical simulations of the nonlinear model indicate that for changes in productivity of up to $10 \%$ the impulse responses of the linear and the nonlinear model are very similar.

For simplicity, I assume that after the increase in productivity $P=\delta /(r+\delta)$ so that in steady state $\bar{h}=h^{*}=1 / 2$, which allows to focus on the more interesting model parameters. Then, the linearized system is given by,

$$
\dot{X}=A X, \quad X=\left[\begin{array}{c}
\hat{L} \\
\hat{h} \\
\hat{N} \\
\hat{n}
\end{array}\right], \quad A=\left[\begin{array}{cccc}
-\delta & -\delta & \delta & 0 \\
-(r+\delta) & r+\delta & r+\delta & -1 \\
0 & 0 & 0 & 1 \\
0 & \frac{\alpha w}{\phi N^{*}} & \frac{\alpha w}{\phi N^{*}} & r
\end{array}\right]
$$

where $\hat{L}=\left(L-L^{*}\right) / L^{*}, \hat{h}=\left(h-h^{*}\right) / h^{*}$ and $\hat{N}=\left(N-N^{*}\right) / N^{*}$ are written in terms of relative deviations from steady state, $\hat{n}=n / N^{*}$ and $\alpha=-\ell f^{\prime \prime}(\ell) / f^{\prime}(\ell)$, evaluated in steady state $\ell=h^{*} N^{*}=L^{*}=N^{*} / 2$. It is straightforward to show that the linear system is saddle-path stable. The stable hyperplane is described by the two stable eigenvectors of the matrix $A$. In appendix $\mathrm{A}$, I derive closed-form expressions for the coefficients in the linear policy rules $\hat{h}=\eta_{L} \hat{L}+\eta_{N} \hat{N}$ and $\hat{n}=\nu_{L} \hat{L}+\nu_{N} \hat{N}$ in terms of the model parameters.

Substituting the policy rules into the linearized version of Euler equation (25) gives an expression for $\dot{n}$. Assuming the economy was initially in steady state, immediately

\footnotetext{
${ }^{9}$ Combining the first order conditions for $h$ and $n$ and the envelope conditions for $L$ and $N$ gives a system of two partial differential equations in the policy rules for $h$ and $n$ as functions of the state variables $L$ and $N$. Even in the much simpler model of section 3.1, where there is just one policy rule, there is no closed-form solution for $h(L ; N)$. In that case the policy rule is described by the ordinary differential equation,

$$
r+\delta-\delta \frac{f^{\prime}(L)}{P f^{\prime}(h N)}=\delta[(1-h) N-L] \frac{h N f^{\prime \prime}(h N)}{f^{\prime}(h N)} \frac{h_{L}}{h}
$$

where $h_{L}=h^{\prime}(L)$, which has a closed-form solution only for a quadratic production function.
} 
after the increase in productivity

$$
\frac{\dot{n}}{N^{*}} \simeq\left(\frac{\alpha w}{\phi N^{*}}\left(1+\eta_{N}\right)+r \nu_{N}\right) \hat{N}
$$

The terms multiplying $\hat{L}$ drop out of this expression because if the system was initially in steady state, then $L$ is still in steady state after the increase in productivity because the steady state level for the organizational capital stock does not depend on $P$, so that $\hat{L}=0$. If productivity increases then the steady state employment level $N^{*}$ increases by (5), so that $\hat{N}<0$ immediately after the shock. Then, for $\dot{n}>0$ it must be that the term multiplying $\hat{N}$ is negative. Substituting the expressions for $\eta_{N}$ and $\nu_{N}$ from the appendix and simplifying, we get the following condition for persistence in hiring.

Proposition 2 In the organizational capital model with convex costs of adjusting employment, hiring reaches its highest level not immediately but some time after an increase in productivity if the adjustment costs $\phi$ are sufficiently high and the depreciation rate for organizational capital $\delta$ is sufficiently low. If the steady state level for the fraction of workers employed in organizational tasks equals one half, the exact condition is

$$
\frac{\alpha w}{\phi N^{*}}<\frac{r^{2}}{4 \delta}\left[3 r+2 \delta+\sqrt{(3 r+2 \delta)^{2}+4 \delta(r+\delta)}\right]
$$

For the derivation of condition (28) see appendix A. The condition that $h^{*}=1 / 2$ is for convenience only and for values of $P$ that give rise to a fraction of workers slightly smaller or greater than $1 / 2$ in steady state, condition (28) still holds approximately. As stated in the proposition, the main implication of the condition is that the depreciation rate for organizational capital needs to be sufficiently low and the adjustment costs sufficiently high for the model to generate a hump-shaped impulse response for hiring. Like in proposition 1, a higher depreciation rate makes organizational capital more similar to regular frequent tasks so that the model behaves more like a standard model. Also consistent with the conclusions for the model with non-convex adjustment costs, a higher discount rate makes the role of the intensive margin more pronounced. In the model with convex costs, that result is driven mainly by the $r n$ term in the linearized Euler equation for hiring. A higher interest rate makes firms less willing to incur the cost of fast adjustments today in order to reach the optimal level of employment faster in the future.

Unlike in proposition 1, condition (28) does not specify a range of values for the adjustment costs but just poses a lower bound on $\phi$. That is because with convex adjustment costs adjusting is always costless in the (very) long run, regardless of the size of the adjustment costs. If the costs are not high enough however, it is not worth distorting the intensive margin in order to incur less adjustment costs by adjusting slower. There is a trade-off between the value of $\delta$ and the lower bound on $\phi$. The more sluggish organizational capital is, the lower the adjustment costs can be while the model still generates persistence in hiring. The curvature of the production function $\alpha$ and the wage $w$ are not very important here; they determine the degree to which distortion of the intensive margin results in a pressure for employment adjustment through the $P f^{\prime}(h N)-w$ term in the Euler equation for $n$. 


\section{Organizational capital in an RBC model}

In order to evaluate the quantitative importance of organizational capital for business cycle fluctuations in employment, I evaluate how the predictions from a model with organizational capital compare to those of existing models. In this section, I first present a few stylized facts on business cycle fluctuations in employment. Then, I add some realism to the model in the previous section by relaxing its most restrictive simplifying assumptions, simulate it and compare the model predictions to these facts.

The model in sections 2, 3 and 4 is deliberately simple in order to focus on the main model elements that drive the results. But it is too simple to allow for a comparison to the data. The extended organizational capital model with convex adjustment costs is a general equilibrium model with a more general form for the production function and a stochastic process for productivity shocks. With convex adjustment costs linearizing provides a good approximation of the dynamics of the nonlinear model and the linearization allows to analyze the model in this more general setup. The natural point of reference is a standard real business cycle (RBC) model, of which the extended model is an extension with with convex adjustment costs in employment and organizational capital.

\subsection{Business cycle facts}

The movement of employment over the business cycle is often summarized by its standard deviation relative to that of output and a set of cross-autocorrelations of log employment with $\log$ output at time $t+s$. Three stylized facts emerge from that analysis: employment is $(i)$ about as volatile as output, $(i i)$ strongly procyclical, but (iii) lags output by one to two quarters. In a compilation of business cycle statistics from aggregate postwar US time series data, Stock and Watson (1999) find that in eight broad sectors of the US economy, the volatility of employment ranges from about $50 \%$ to $220 \%$ of the standard deviation in log output. Employment is procyclical in all sectors. In the more cyclical sectors (construction, manufacturing, service, wholesale and retail and transportation), employment lags output by 1 to 2 quarters, in the sense that the correlation of log employment is highest with log output lagged by 1 to 2 quarters. In the less cyclical sectors (finance and real estate, mining and government) that lag is even longer: 2 to 5 quarters. Aggregate employment has a relative standard deviation of 0.84, a contemporaneous correlation with output of 0.81 and a maximum correlation of 0.92 after one quarter. These stylized facts are similar for business cycles in other countries (Backus, Kehoe and Kydland 1995, Millard, Scott and Sensier 1997).

\subsection{The extended model}

Consider an economy populated by a continuum of workers. Each worker owns a firm and all firms produce a homogeneous consumption good. The representative worker decides how many hours $N$ to work in her firm as well as how much of its output to consume. She solves an intertemporal utility optimization problem, with utility $u(c)+$ $(1-N) \gamma$ additively separable and linear in leisure. The utility gain from not working $\gamma$ can be interpreted as utility from leisure, home production, unemployment benefit or 
commuting costs. I maintain the assumption that utility over leisure is linear because I interpret $N$ as employment in persons. ${ }^{10}$

Output that is not consumed can be invested to build up the stock of physical capital $K$. This provides a mechanism for workers to smooth their consumption. Because all workers and all firms are identical, the intertemporal budget constraint of the representative worker equals the aggregate resource constraint.

$$
\dot{K}=Y-c-\delta_{K} K
$$

where $c$ is consumption of the representative agent as well as aggregate consumption, $K$ is the aggregate capital stock and $\delta_{K}$ is the depreciation rate of (physical) capital. The return on capital is endogenous because capital enters in the production function, which is a slightly extended version of production function (21).

$$
Y=A K^{\alpha}\left[(1-\beta)(P h N)^{\theta}+\beta L^{\theta}\right]^{\frac{1-\alpha}{\theta}}
$$

Productivity $P$ is stochastic and follows and Itô process with stochastic differential equation,

$$
d P=-\mu P \log P d t+\sigma P d z
$$

where $z$ is a standard Brownian motion, $d z \sim N(0, d t), \mu$ is a drift parameter and $\sigma$ is the standard deviation of innovations in $\log P$. This is an Ornstein-Uhlenbeck process (the equivalent of a first-order autoregressive process in discrete time) in $\log P$, which guarantees that $P$ is always positive. Because the drift is positive if $P<1$ and negative if $P>1$, the process is mean-reverting towards $\bar{P}=1$. Productivity, capital and consumption have been divided by a common trend component to remove long run growth from the model and the mean of the resulting productivity variable $P$ is normalized to one. The parameter $\mu$ measures the degree of mean-reversion with $\mu=0$ for permanent shocks and $\mu>0$ for transitory shocks to productivity.

With these extensions, the capital stock $K$ and productivity $P$ are added to the state vector and consumption $c$ becomes a choice variable. The representative agent solves the following stochastic dynamic optimization problem,

$$
V(L, N, K, P)=\max _{h, n, c} E \int_{0}^{\infty} e^{-\rho t}\left[u(c)+(1-N) \gamma-\frac{1}{2} \phi n^{2}\right] d t
$$

where $\rho$ is the discount rate, subject to the law of motion for organizational capital (2), the aggregate resource constraint (29) with production $Y$ as in (30), the law of motion for employment (22) and the stochastic process for productivity (31). For convenience I define the adjustment costs as direct reductions in utility. Notice that profit maximization problem (3) is a special case of (32) if $K$ is fixed, utility over consumption $u($.$) is linear, the discount rate equals the interest rate \rho=r$ and the wage equals the reservation wage $w=\gamma$.

\footnotetext{
${ }^{10}$ To make it more natural to think of $N$ as employment in persons, the problem can be interpreted as the intertemporal optimization problem of a representative household that owns a firm and decides how many of its members to send to work. Because of exogenous constraints, workers can only work in the firm full time, as in Hansen (1985).
} 
The first order and envelope conditions of problem (32) can be combined to give Euler equations for consumption $c$, the fraction of worker in current productive tasks $h$ and hiring $n$, and an envelope condition for the shadowprice of productivity $V_{P}$. These form a system of four partial differential equations in the policy rules or, together with the four constraints, a system of eight stochastic ordinary differential equations in the model variables as functions of time. In appendix B, I derive these equations, linearize the system and outline the solution method for the linearized policy rules. In the linearized model there is certainty equivalence: the policy rules and therefore the impulse functions do not depend on the degree of uncertainty $\sigma$.

\subsection{Calibration}

For comparability, I follow the parameterization of a standard RBC model as in King and Rebelo (1999). Utility over consumption is logaritmic, corresponding to an intertemporal elasticity of substitution and a coefficient of relative risk aversion both equal to one. This is the only additively separable utility function that has the balanced growth property: permanent changes in productivity do not lead to permanent changes in employment. The capital share $\alpha$ in the production function is one third, and the depreciation rate of capital is set to $10 \%$ per year.

For the discount rate $\rho$, King and Rebelo use a value of $6.5 \%$ per year, the average return on the S\&P500 index from 1948 to 1986. A concern in setting this parameter, is that it strongly affects the consumption-output ratio in steady state. In King and Rebelo's calibration, this ratio is roughly equal to the observed value of 0.7 . But in the standard RBC model, $N$ is interpreted as hours worked by the representative agent, whereas in (32) I interpret $N$ as employment in persons so that utility is linear in leisure (King and Rebelo use a logaritmic specification). With linear utility over leisure, a discount rate of $6.5 \%$ implies a consumption-output ratio that is much too high, so I use a $4 \%$ discount rate instead, which implies that consumption is about $75 \%$ of output in steady state. This value for the discount rate is closer to the risk-free rate and has been used among others by Kydland and Prescott (1982) and Hansen (1985). Because a higher discount rate makes it more likely that the model displays delayed hiring, see (28), using a lower discount rate also makes sure that the results are not driven by an implausibly high value for this parameter.

Following Prescott (1986), King and Rebelo use an AR(1) process for log total factor productivity, which they estimate from empirical Solow residuals. The first order autocorrelation parameter equals 0.979 and the variance of its innovations is 0.0072 per quarter. With $\beta=0, \log$ total factor productivity in (30) equals $\log A+(1-\alpha) \log P$, where $A$ is a constant. Discretizing (31) in quarterly intervals, $\log P$ follows an $\operatorname{AR}(1)$ process with autocorrelation coefficient $1-\mu$ and normally distributed innovations with variance $\sigma^{2}$, so that $1-\mu$ is also the autocorrelation parameter for log total factor productivity and $(1-\alpha) \sigma$ is its standard deviation. Therefore, I set $\mu=0.007$ and $\sigma=0.0042 /(1-\alpha)$ per month.

The remaining parameters are specific to the organizational capital model. In the baseline simulations, I use $\theta=1-\alpha$ so that total labor input is additively separable in current productive activities and organizational capital, and vary the remaining parameters $\phi, \beta$ and $\delta$. 


\subsection{Simulations}

A calibrated real business cycle model describes the aggregate time series data reasonable well, in the sense that the standard deviations and correlations predicted by the model are close to the ones observed in the data (Prescott 1986). The first row of panel A in table 1 presents standard deviations, autocorrelations and correlations with output of some key variables in the data. The second row presents the same moments for the standard RBC model (where $N$ is interpreted as hours worked). These moments were calculated by using the calibrated model to generate 2,500 years (10,000 quarters) of simulated 'data' and detrending these time series using a Hodrick-Prescott filter with a smoothing parameter of 1600 . The results are almost identical to those reported by King and Rebelo (1999). ${ }^{11}$

Comparing the simulations to the data in the first row, reveals a number of well documented facts about the performance of RBC models. The volatility of output predicted by the model is about $80 \%$ of the volatility observed in the data and the model correctly predicts that investment is about 3 times more volatile than output. But the model has weak internal amplification and propagation mechanisms (Cogley and Nason 1995, Rotemberg and Woodford 1996). Labor input is crucial to the RBC model, yet the relative volatility of employment in the standard model is substantially lower than in the data and the model counterfactually predicts almost perfect correlation of employment with output (Kydland 1995, King and Rebelo 1999). Because employment is not volatile enough, also labor productivity is far more procyclical than in the data.

Modelling labor supply along the extensive margin, in terms of the number of employed workers, rather than in terms of hours per worker (Rogerson 1988, Hansen 1985) or modelling both a participation and an hours decision (Cho and Cooley 1994), improves the model in terms of the relative volatility of employment and output. This is illustrated in the third row, which presents simulated moments for the recalibrated model, in which $N$ is interpreted as employment in persons. These statistics are very similar to those reported by Hansen. Employment becomes more volatile and labor productivity less procyclical, but employment is still almost perfectly correlated with output and the persistence predicted by the model does not change and remains too low.

One natural way to build in more persistence is to introduce adjustment costs. Cogley and Nason (1995) evaluate the performance of a number of different models and find that adjustment costs (or lags in employment adjustment as in Burnside, Eichenbaum and Rebelo 1993) improve the model's ability to reproduce the observed autocorrelation pattern for output. The next three rows explore this effect. As the adjustment costs increase, the model predicts a higher autocorrelation in employment and output but the volatility of employment decreases, taking the model further from the data along that dimension. ${ }^{12}$ For $\phi=10$ the model with adjustment costs in employment matches the autocorrelation in employment observed in the data, at the cost of a 35\% drop in the

\footnotetext{
${ }^{11}$ The small differences are because of a small correction to the aggregate resource constraint for long run growth, which I ignore. The correct discrete time version of $(29)$ is $(1-g) K_{t+1}=\left(1-\delta_{K}\right) K_{t}+Y-c$, where $g$ is the common growth rate along the balanced growth path. King and Rebelo set $g=0.4 \%$ per quarter, consistent with the average growth of per capital output in the postwar US data.

${ }^{12}$ For low $\phi$ the relative volatility of employment slightly increases because the standard deviation of output decreases by more than that of employment.
} 
relative volatility of employment.

Adjustment costs in employment also break the perfect comovement of employment with output. Panel B provides some insight into why this happens. I report correlations of employment with 6 lags and leads of output for the different models, which may again be compared to the correlations calculated from the data in the first row. ${ }^{13}$ In the standard RBC model, the correlation of employment is highest with contemporaneous output. With adjustment costs in employment, the peak correlation between employment and output declines very little, but employment starts to lag output, which reduces the contemporaneous correlation.

Now consider the last eight rows of panels A and B, which present simulated moments for the model with organizational capital. I vary the adjustment costs $\phi$ and the depreciation rate of organizational capital $\delta$ and set the share of organizational capital in the production function to match the persistence in employment in the data. The first column reports the fraction of workers that perform organizational tasks in steady state. As expected, higher adjustment costs or a slower depreciating organizational capital stock imply that for a smaller share of organizational capital in production, the model generates enough persistence in employment. For low depreciation rates, the fraction of workers allocated to organizational tasks is very small.

Because the model with organizational capital requires lower adjustment costs than the model with adjustment costs only to generate enough persistence in employment, the volatility of employment and therefore the volatility of output decreases less in these models (compared to the adjustment costs model with $\phi=10$, which matches the persistence in employment). The model with organizational capital does as well as the model with adjustment costs in generating the lag in employment with respect to output, but matches the data slightly better in the sense that it generates enough persistence in employment for more reasonable values of the adjustment costs. ${ }^{14}$

\section{Impulse response functions}

From the simulations in the previous section, it seems that the effect of organizational capital is similar to that of adjustment costs in employment. But unconditional moments can only give a partial picture of the model behavior. In fact, the underlying dynamics are very different for the organizational capital model and the model with convex adjustment costs only. In order to better understand what drives the persistence

\footnotetext{
${ }^{13}$ The cross-autocorrelations for the actual data are taken from Stock and Watson (1999). Stock and Watson focus on the 'cyclical component' of employment and output, using a bandpass filter that isolates cyclical fluctuations with periodicities between 6 quarters and 8 years. However, their results are similar to those using the HP filter, which removes only low frequency fluctuations.

${ }^{14}$ An alternative criterion for a reasonable value for $\phi$ is the fraction of the consumption good that is lost because of adjustment costs. It turns out however, that in this sense the adjustment costs are always negligible. With a logaritmic utility function over consumption, the amount of adjustment costs paid $\frac{1}{2} \phi n^{2}$ can be immediately interpreted as a fraction of consumption, $\frac{1}{2} \phi n^{2}=u(c)-u(c-\Delta c) \simeq \Delta c / c$, where $\Delta c$ is the amount of consumption that would have to be sacrificed to make the representative agent equally well off if she did not have to pay the adjustment costs. For all values of $\phi$ in the table, $\frac{1}{2} \phi n^{2}$ is smaller than $10^{-7}$. The reason is that as the adjustment costs increase, the amount of hiring $n$ decreases. A reasonable value for $\phi$ therefore, is a value that gives rise to a realistic amount of hiring and employment volatility.
} 
in employment generated by the model, I present impulse response functions and compare these to the standard RBC model and the model with adjustment costs. Impulse responses also allow to better evaluate the role of the different parameters associated with organizational capital.

\subsection{Contribution of organizational capital}

Figure 3 presents impulse response functions for the standard RBC model (solid lines) as well as for the standard model with adjustment costs in employment (dashed lines) to a permanent positive productivity shock $(\mu=0) .{ }^{15}$ In the standard RBC model, all persistence in employment is driven by transition dynamics in the capital stock. In response to the increase in productivity, output immediately increases almost to its steady state level, but consumption increases by less than its eventual increase. ${ }^{16}$ The difference is invested, so that the capital stock gradually converges to a higher level that sustains the permanently higher production and consumption levels. Employment initially increases because the increase in productivity raises the marginal product of labor. In the long run, when capital has reached its new higher level, employment goes back to the level before the increase in productivity. This is because balanced growth preferences guarantee that in the long run the substitution and income effect of productivity on employment cancel out.

The fact that in the standard model the response of employment is largest immediately after the change gives rise to the almost perfect comovement of employment with output, which also experiences the largest change right after the increase in productivity. Employment is not lagged with respect to output, and there is no endogenous persistence in employment over and above the persistence in the transition of the capital stock. With adjustment costs, employment becomes a state variable and can no longer jump to its highest level immediately. Therefore, employment responds with a lag compared to output. There is some additional persistence in employment which is driven by the adjustment costs. The success of this model stops however, when we look at the response of employment adjustments. Hiring jumps to its highest level immediately after the productivity shock. This is a standard result in models with convex adjustment costs but inconsistent with evidence on persistence in the hiring rate.

Figure 4 zooms in on the beginning of the boom and introduces organizational capital. Because firms now have a second margin of adjustment available to respond to the increase in productivity, there is no immediate need for hiring. Initially, the fraction of workers allocated to productive tasks jumps up substantially (by almost $1 \%$ in response to a $1 \%$ increase in productivity). At that point there is little hiring, because the intensive margin absorbs most of the shock. Then, as the organizational capital stock starts to decrease, some of these workers are allocated back to organizational tasks. As this happens, the need to have more employed workers becomes more urgent and hiring increases. But during the same time also employment and the physical capital stock have

\footnotetext{
${ }^{15}$ Because the stochastic process for productivity shocks used for the simulations is highly persistent, the impulse responses for these shocks are similar to those for permanent shocks. The main difference is that as the productivity shock dies out, so do the responses of all model variables. Following the literature, I present impulse responses to permanent shocks, which are easier to interpret.

${ }^{16}$ With a different calibration consumption may initially even decrease
} 
increased. As employment approaches its peak level, hiring decreases again (eventually becoming negative to bring employment back to its pre-shock level in the long run).

Persistence in employment in the organizational capital model is driven by persistence in employment growth. The standard real business cycle model has little to say about the hiring rate because a theory of job search is absent from this model. ${ }^{17}$ In the presence of search frictions, a worker that loses or quits her job does not immediately find a new employer and therefore remains unemployed for a period while she searches. This introduces an additional source of persistence in employment fluctuations. Yet standard search models (Mortensen and Pissarides 1994) do not predict enough persistence in employment (Cole and Rogerson 1999) and do not not generate enough volatility in hiring (Shimer 2004) to match business cycle fluctuations. Evidence from worker flow data indicates that only a a very small fraction of persistence in unemployment is caused by transition dynamics of the employment rate to its steady state level, the remainder by persistent fluctuations in employment growth and in particular in the hiring rate (Shimer 2002, Hall 2004, 2005). Therefore, to understand why employment remains low after the end of a recession, we must understand why the hiring rate remains low. Organizational capital offers a possible explanation. Even a small amount of persistence in the hiring rate makes employment fluctuations very persistent, see table 1 .

\subsection{Role of the parameters}

\subsubsection{Organizational capital share in the production function}

The share of organizational capital in the production function is crucial for the shape of the impulse responses in figure 4 . This is illustrated in figure 5 where impulse responses are plotted for three different values of the steady state fraction of workers in organizational tasks. If organizational capital is a relatively unimportant part of total labor input in production, the hump-shaped impulse response in hiring becomes less pronounced and for very low $\beta$ the responses for hiring and employment look like those in figure 3 for the model with adjustment costs but without organizational capital. On the other hand, if organizational capital is very important in production, the intensive margin effect may become so important that $n$ initially jumps down. Even though employment has to increase in the medium-long run in response to an increase in productivity, initially some workers are fired. ${ }^{18}$ Why is this optimal?

When productivity increases the optimal allocation is distorted. During the transition dynamics, firms can take advantage of the intensive margin of adjustment because of the labor that is 'stored' in the form of organizational capital. When they start using this stored labor, the marginal product of labor in the firm temporarily decreases. If organizational capital is very important, the net effect on the marginal product of labor may be negative. In that case it is optimal to temporarily fire some workers because

\footnotetext{
${ }^{17}$ Hall (1999) argues that this is the reason for the failure of standard RBC models to describe the properties of employment fluctuations observed in the data.

${ }^{18}$ One might interpret this result as indicating that the organizational capital model is consistent with a number of recent VAR papers, which find that the initial response of employment (or total hours) to an increase in productivity is negative (Galí 1999, Francis and Ramey 2002, Basu, Fernald and Kimball 2004, Galí and Rabanal 2004). There is considerably disagreement in the literature about the response of employment to a productivity shock, with other papers finding that the initial response is positive (Christiano, Eichenbaum and Vigfusson 2003), in all cases with large error bands.
} 
their marginal product is lower than the value of leisure. When the intensive margin gets depleted the marginal product of labor increases and these workers are hired again.

\subsubsection{Substitution between tasks}

Another parameter that is important for the behavior of the model is $\theta$, which determines the degree to which firms can substitute between the two different types of tasks. For an increase in productivity to have a positive effect on the fraction of workers $h$ allocated to current production, $\theta$ needs to be sufficiently greater than zero. There are two potential reasons for this parameter restriction. First, a higher $\theta$ makes it easier for firms to substitute current productive tasks for organizational capital and vice versa. Second, a higher $\theta$ makes $P$ have a larger effect on the relative productivity of current productive tasks over organizational capital. To see which of these two effects is important, I simulated the model replacing $L$ by $P L$ in production function (30). In this specification, $\theta$ still affects the elasticity of substitution between organizational and productive tasks, but the effect of $P$ on the productivity of both types of tasks is always symmetric. In this case the parameter $\theta$ has virtually no effect on the simulated impulse responses. Therefore, I conclude that it is the effect of changes in $P$ on the relative productivity of the two types of tasks which is important for the results.

If organizational capital is to be relevant for business cycle fluctuations, we need to think of a boom as a period of high relative productivity of current productive tasks. Organizational tasks are no more productive than in a recession. Then, because labor overall is more valuable, firms will substitute organizational tasks for productive tasks in a boom and vice versa in a recession. Even though the optimal level of organizational capital is the same in a boom and in a recession, the actual level differs because of this substitution between tasks. ${ }^{19}$

\subsubsection{Transitory productivity shocks}

Transitory shocks to productivity have a larger effect on the productivity of current productive tasks than on organizational tasks even if both types of tasks are not very good substitutes. A transitory increase in $P$ affects the productivity of current productive tasks, but not the productivity of productive tasks in the future. But organizational tasks affect production both now and in the future, so that the productivity of organizational tasks today depends on the productivity of organizational capital both today and in the future. Therefore, a transitory productivity shock increases the relative productivity of current productive activities over organizational tasks.

Quantitatively, this effect turns is not very important. This is illustrated in figure 6, which presents impulse responses for the model with a Cobb-Douglas production function $(\theta=0$, so that permanent productivity shocks have a symmetric effect on the productivity of the two types of tasks) for different values of the persistence parameter $\mu$. More transitory shocks indeed have a slightly larger initial effect on the allocation between current productive and organizational tasks $h$, but the effect is very small and

\footnotetext{
${ }^{19}$ Once current productive tasks and organizational capital are sufficiently good substitutes, further increases in $\theta$ are hard to distinguish from increases in the organizational capital share $\beta$ so I set $\theta=1-\alpha$ in most simulations, which has the intuitive appeal that the production function is additively separable so that changes in productivity do not at all affect the productivity of organizational capital.
} 
despite the very high fraction of workers assigned to organizational tasks $\left(h^{*}=0.5\right)$, the impulse response for hiring is never increasing after the initial jump.

\subsubsection{Depreciation rate organizational capital and adjustment costs}

Finally, consider the role of the adjustment $\operatorname{costs} \phi$ and the depreciation rate of organizational capital $\delta$. Since $\phi$ and $\delta$ affect the shape of the impulse responses as well as the time scale it is hard to make a meaningful comparison between the impulse responses for different values for $\phi$ and $\delta$ keeping all other parameters constant. Therefore, I use the share parameter for organizational capital in production $\beta$ to make the impulse responses better comparable. I simulate the model for a range of values for $\phi$ and $\delta$, setting $\beta$ such that hiring does not jump either up or down immediately after the shock. This is the case of a perfect jobless recovery, where $\dot{N}=0$ immediately after an increase in productivity. Panel A in table 2 presents the resulting steady state fraction of workers in current productive activities. Because the shape of the impulse responses for hiring is the same across simulations, these responses can be conveniently summarized by the length of the delay after the increase in productivity before hiring reaches its maximum level and the height of that maximum. Panels B and C in table 2 present these summary statistics.

Proposition 2 states that in the simple model, given a fixed share of organizational capital in the production function, there is a lower bound on the adjustment costs $\phi$ and an upper bound on the depreciation rate of organizational capital $\delta$. This is no different in the full model. For a given value for $\phi$, as the depreciation rate of organizational capital gets higher, a higher fraction of workers assigned to organizational tasks is necessary for the model to display persistence in hiring and the duration of the delay becomes shorter. For a given value of $\delta$, as the adjustment costs decrease, the duration of the delay becomes shorter as well. In practice, there is also an upper bound on the adjustment costs. For high $\phi$, the maximum amount of hiring becomes very small so that the volatility of employment rapidly decreases, and hiring is persistent only if a large fraction of the workforce are performing organizational tasks in steady state.

For reasonable values of the adjustment costs, the model predicts delays in hiring from less than three months to over a year if the economy is originally in steady state. If organizational capital is sufficiently persistent ( $\delta$ sufficiently low), the model predicts substantial delays in hiring even if the fraction of workers allocated to organizational tasks is very small.

\subsection{Jobless recoveries}

Because in response to an increase in productivity hiring starts only gradually, employment initially does not increase at all or may initially even decrease. In that sense, the impulse response for employment generated by the model looks like a jobless recovery. In most past recessions employment remained low for a few months after the trough date, but after the recessions that ended in March 1991 and November 2001 employment has been particularly slow to recover. After these recessions, it took 14 and 29 months respectively for employment to return to the level it was at the NBER trough date. For comparison, on average after the five recessions in the 1960s, 70s and 80s after

the recession ended, employment reached the level of the previous peak after about 9 
months (Schreft and Singh 2003, Aaronsson, Rissman and Sullivan 2004). The delays in hiring predicted by the model are of the same order of magnitude as these long jobless recoveries.

Clearly a theory of jobless recoveries should explain why the the jobless period was so much longer after the 1991 and 2001 than in earlier recoveries. The organizational capital model offers an explanation that is at least qualitatively consistent with the data. The 1991 and 2001 recessions followed two of the three longest booms in the history of the NBER chronology, 92 and 120 months respectively. ${ }^{20}$ According to the model, organizational capital is depleted at the beginning of an expansion and then built up again as the expansion continues and employment increases. If organizational capital is very persistent, it would still be below steady state after a relatively short expansion. In that case the intensive margin of labor adjustment is only available to a limited extent, and employing more workers is optimal after a short lag. After a long expansion on the other hand, firms have been rebuilding their organizational capital stock during the expansion and there is room to postponse organizational tasks for substantial amounts of time after the end of the recession.

This explanation is related to, but different from the one offered by Koenders and Rogerson (2004). Consistent with the argument in this paper, Koenders and Rogerson argue that reorganizations will be postponed when productivity is relatively high. There are two main differences. First, in their view reorganizations involve shedding of labor, whereas in the model in this paper reorganization requires labor. Second, in their model reorganization is postponed as long as the expansion lasts, whereas in this paper postponing organizational tasks is a temporary solution. The prediction of both models is that jobless recoveries follow long expansions. In the Koenders and Rogerson framework this is because reorganizations have been postponed for so long that the recession is not long enough to remove all inefficiencies. In the model of this paper, most inefficiencies have been eliminated at the end of a long expansion so that organizational tasks can be postponed after the recession ends.

\section{Conclusions}

This paper presents a model in which production requires organizational capital and analyzes its predictions for employment fluctuations. Organizational capital is accumulated by workers performing organizational tasks. Organizational tasks differ from regular productive tasks because their effect on production is not immediate but lasts for a period of time. This provides firms with a mechanism to intertemporally substitute labor input by postponing organizational tasks when the productivity of regular productive tasks is relatively high. I label this the intensive margin of labor adjustment.

In the presence of fixed adjustment costs in employment, it is optimal to delay employment adjustments in response to productivity shocks and reallocate workers within the firm instead. By using the intensive margin of adjustment, firms can postpone the adjustment costs, lowering these costs from a net present value perspective. Unlike in

\footnotetext{
${ }^{20}$ Koenders and Rogerson (2004) present evidence that, after detrending the data, employment was very slow to recover also after the 1970 recession, which followed the third of the three longest expansions since 1854 .
} 
most models with non-convex adjustment costs, this result carries over to the case of convex adjustment costs in employment. With convex adjustment costs there is an incentive to adjust employment gradually. While employment has not yet reached its new optimal level in response to a change in productivity, firms use the intensive margin of adjustment. As the stock of organizational capital is gradually depleted, the need for adjusting employment becomes more urgent, so that the highest amount of hiring or firing occurs a while after productivity changes.

To evaluate the quantitative relevance of this mechanism, I simulated a dynamic stochastic general equilibrium model with organizational capital and (convex) adjustment costs in employment. The simulations indicate that even if the fraction of workers (or the fraction of time spent by each worker) performing organizational tasks is low, the model generates persistent fluctuations in employment, driven by dynamics for hiring and firing that are very different from standard models. The model not only explains why employment fluctuations are persistent and why employment lags output over the business cycle, but it does so in a way that is consistent with evidence that employment growth is persistent. In response to an increase in productivity, hiring increases gradually as if there were adjustment costs in the hiring rate instead of in employment. For this result to go through, the depreciation rate of organizational capital needs to be sufficiently low and organizational capital and regular productive tasks need to be sufficiently good substitutes so that an increase in productivity increases the relative productivity of regular productive tasks over organizational tasks.

\section{A Linearized model with convex adjustment costs}

Consider the 4-by-4 linear system of differential equations in (26). For $r>0, \delta>0$, $\alpha>0, w>0$ and $\phi>0$ the matrix $A$ has two eigenvalues with positive and two with negative real parts so that the system is saddle path stable. The eigenvalues are given by

$$
\lambda_{i}=\frac{1}{2} r \pm \frac{1}{2} \sqrt{r^{2}+4 \delta\left(r+\delta \pm \sqrt{\left.(r+\delta)^{2}-2 \frac{\alpha w}{\phi N^{*}} \frac{r+\delta}{\delta}\right)}\right.}
$$

for $i=1,2,3,4$. Notice that if

$$
\frac{\alpha w}{\phi N^{*}}=\frac{\alpha w^{\frac{1+\alpha}{\alpha}}}{2 \phi}\left(\frac{r+\delta}{\delta}\right)^{1 / \alpha}>\frac{1}{2} \delta(r+\delta)
$$

then the eigenvalues are complex. Denote the stable eigenvalues (for which the first \pm is a minus) by $\lambda_{1}$ and $\lambda_{2}$ with $\operatorname{Re} \lambda_{1}<0$ and $\operatorname{Re} \lambda_{2}<0$. The eigenvectors corresponding to eigenvalues $\lambda_{i}$ are

$$
v_{i}=\left[\begin{array}{c}
v_{i L} \\
v_{i h} \\
v_{i N} \\
v_{i n}
\end{array}\right]=\left[\begin{array}{llll}
-\frac{\left(r-\lambda_{i}\right)\left(r+\delta-\lambda_{i}\right)}{(r+\delta)} \frac{\phi N^{*}}{\alpha w} & \frac{\lambda_{i}\left(r-\lambda_{i}\right)^{2}}{2 \delta(r+\delta)} \frac{\phi N^{*}}{\alpha w} & -\frac{\left(r-\lambda_{i}\right)\left(2 \delta(r+\delta)+\lambda_{i}\left(r-\lambda_{i}\right)\right)}{2 \delta(r+\delta)} \frac{\phi N^{*}}{\alpha w} & 1
\end{array}\right]^{\prime}
$$


The stable eigenvectors define the stable hyperplane and the linearized policy rules for $h$ and $n$ are given by

$$
\left[\begin{array}{l}
\hat{h} \\
\hat{n}
\end{array}\right]=\left[\begin{array}{ll}
v_{1 h} & v_{2 h} \\
v_{1 n} & v_{2 n}
\end{array}\right]\left[\begin{array}{ll}
v_{1 L} & v_{2 L} \\
v_{1 N} & v_{2 N}
\end{array}\right]^{-1}\left[\begin{array}{c}
\hat{L} \\
\hat{N}
\end{array}\right]
$$

Substituting and simplifying, the policy rules can be written as

$$
\left[\begin{array}{l}
\hat{h} \\
\hat{n}
\end{array}\right]=\left[\begin{array}{ll}
\frac{(r+\delta)\left(r-\lambda_{1}-\lambda_{2}\right)}{(r+\delta)\left(r+2 \delta-\lambda_{1}-\lambda_{2}\right)+\lambda_{1} \lambda_{2}} & -\frac{(r+\delta)\left(r-\lambda_{1}-\lambda_{2}\right)+\lambda_{1} \lambda_{2}}{(r+\delta)\left(r+2 \delta-\lambda_{1}-\lambda_{2}\right)+\lambda_{1} \lambda_{2}} \\
-\frac{(r+\delta)\left[\left(r-\lambda_{1}-\lambda_{2}\right)^{2}-\lambda_{1} \lambda_{2}-2 \delta(r+\delta)\right] A}{\left(r-\lambda_{1}\right)\left(r-\lambda_{2}\right)\left[(r+\delta)\left(r+2 \delta-\lambda_{1}-\lambda_{2}\right)+\lambda_{1} \lambda_{2}\right]} & -\frac{2 \delta(r+\delta)\left(2 r+\delta-\lambda_{1}-\lambda_{2}\right) A}{\left(r-\lambda_{1}\right)\left(r-\lambda_{2}\right)\left[(r+\delta)\left(r+2 \delta-\lambda_{1}-\lambda_{2}\right)+\lambda_{1} \lambda_{2}\right]}
\end{array}\right]\left[\begin{array}{c}
\hat{L} \\
\hat{N}
\end{array}\right]
$$

To prove proposition 2 , substitute the policy rules into (27)

$$
\frac{\dot{n}}{N^{*}} \simeq \frac{2 \delta(r+\delta)\left[\lambda_{1} \lambda_{2}-r(r+\delta)\right]}{\left(r-\lambda_{1}\right)\left(r-\lambda_{2}\right)\left[(r+\delta)\left(r+2 \delta-\lambda_{1}-\lambda_{2}\right)+\lambda_{1} \lambda_{2}\right]} \frac{\alpha w}{\phi N^{*}} \hat{N}
$$

and because $r>0, \delta>0, \alpha>0, w>0, \phi>0, N^{*}>0, \operatorname{Re} \lambda_{1}<0, \operatorname{Re} \lambda_{2}<0$ and $\hat{N}<0$ this implies that $\dot{n}>0$ if and only if ${ }^{21}$

$$
\lambda_{1} \lambda_{2}<r(r+\delta)
$$

Because the eigenvalues may be complex, this condition cannot be immediately interpreted in terms of the model parameters. If $\lambda_{1}$ and $\lambda_{2}$ are complex then they are complex conjugates so that $\lambda_{1} \lambda_{2}$ is real, otherwise $\dot{n}$ would be complex. First, use the expressions for $\lambda_{1}$ and $\lambda_{2}$ to evaluate $\lambda_{1} \lambda_{2}$,

$$
\begin{aligned}
\lambda_{1} \lambda_{2}= & \frac{1}{4} r^{2}+\frac{1}{4} \sqrt{r^{4}+8 \delta(r+\delta)\left(r^{2}+4 \frac{\alpha w}{\phi N^{*}}\right)} \\
& -\frac{1}{4} r\left(\sqrt{r^{2}+4 \delta(r+\delta)+4 \delta Q}+\sqrt{r^{2}+4 \delta(r+\delta)-4 \delta Q}\right)
\end{aligned}
$$

where

$$
Q=\sqrt{(r+\delta)^{2}-2 \frac{\alpha w}{\phi N^{*}} \frac{r+\delta}{\delta}} \in \mathbb{C}
$$

Next, take the first two terms to the left-hand side, square both sides of the equation and simplify to get the following quadratic equation for $\lambda_{1} \lambda_{2}$.

$$
16\left(\lambda_{1} \lambda_{2}\right)^{2}-8 \lambda_{1} \lambda_{2}\left(r^{2}+\sqrt{r^{4}+8 \delta(r+\delta)\left(r^{2}+4 \frac{\alpha w}{\phi N^{*}}\right)}\right)+32 \delta(r+\delta) \frac{\alpha w}{\phi N^{*}}=0
$$

Notice that $Q$ drops out and because the discriminant is positive this equation always has real solutions. Of course this equation has two roots for $\lambda_{1} \lambda_{2}$, only one of which is

\footnotetext{
${ }^{21}$ Because $\lambda_{1}$ and $\lambda_{2}$ are complex conjugates with a negative real part, $\lambda_{1}+\lambda_{2}=2 a<0$ where $a=\operatorname{Re} \lambda_{1}=\operatorname{Re} \lambda_{2}$ and $\lambda_{1} \lambda_{2}=a^{2}+b^{2}>0$ where $b=\operatorname{Im} \lambda_{1}=\operatorname{Im} \lambda_{2}$. Therefore $\left(r-\lambda_{1}\right)\left(r-\lambda_{2}\right)=$ $r^{2}-r\left(\lambda_{1}+\lambda_{2}\right)+\lambda_{1} \lambda_{2}>0$ so that the denominator is always real and positive.
} 
the solution. Substituting $\lambda_{1} \lambda_{2}=r(r+\delta)$, rearranging and squaring, we get a quadratic equation in the candidate lower bound for $\phi$.

$$
\left(\frac{4 \delta \alpha w}{r \underline{\phi} N^{*}}\right)^{2}-2 r(3 r+2 \delta) \frac{4 \delta \alpha w}{r \underline{\phi} N^{*}}-4 r^{2} \delta(r+\delta)=0
$$

This equation has only one positive root, so that

$$
\frac{4 \delta \alpha w}{r \underline{\phi} N^{*}}=r\left(3 r+2 \delta+\sqrt{(3 r+2 \delta)^{2}+4 \delta(r+\delta)}\right)
$$

defines the only positive candidate lower bound for $\phi$. Since for $\phi \rightarrow 0, \lambda_{1} \lambda_{2} \rightarrow \infty>$ $r(r+\delta)$ and for $\phi \rightarrow \infty, \lambda_{1} \lambda_{2}=0<r(r+\delta)$ there has to be a positive lower bound for $\phi$ so it must be that the candidate $\phi$ is indeed the lower bound, which proves the proposition in the text.

\section{B The extended RBC model}

The recursive formulation of the representative agent's problem (32) is given by the following Bellman equation.

$$
\rho V(L, N, K, P)=\max _{h, n, c}\left\{u(c)+(1-N) \gamma-\frac{1}{2} \phi n^{2}+\frac{E[d V]}{d t}\right\}
$$

Because the state vector $[L, N, K, P]^{\prime}$ follows a multivariate Itô process defined by (2), (22), (29) and (31), the value function is an Itô process as well, and by Itô's lemma

$$
\begin{aligned}
\frac{E[d V]}{d t}= & \delta[(1-h) N-L] V_{L}+n V_{N} \\
& +\left[f(P h N, L, K)-c-\delta_{K} K\right] V_{K}-\mu P \log P V_{P}+\frac{1}{2} \sigma^{2} P^{2} V_{P P}
\end{aligned}
$$

where $f$ is the production function for the consumption good as in (30).

The first order conditions for consumption $c$, the fraction of workers in current productive activities $h$ and hiring $n$,

$$
\begin{aligned}
V_{K} & =u^{\prime}(c) \\
\delta V_{L} & =P f_{1} V_{K}=u^{\prime}(c) P f_{1} \\
V_{N} & =\phi n
\end{aligned}
$$

and the envelope conditions for $L, N, K$ and $P$ are given by,

$$
\begin{aligned}
(\rho+\delta) V_{L} & =f_{2} V_{K}+\frac{E\left[d V_{L}\right]}{d t} \\
\rho V_{N} & =-\gamma+\delta(1-h) V_{L}+P h f_{1} V_{K}+\frac{E\left[d V_{N}\right]}{d t}=P f_{1} V_{K}-\gamma+\frac{E\left[d V_{N}\right]}{d t} \\
\rho V_{K} & =\left(f_{3}-\delta_{K}\right) V_{K}+\frac{E\left[d V_{K}\right]}{d t} \\
(\rho+\mu) V_{P} & =h N f_{1} V_{K}-\mu \log P V_{P}+\sigma^{2} P V_{P P}+\frac{E\left[d V_{P}\right]}{d t}
\end{aligned}
$$


where

$$
\begin{aligned}
\frac{E\left[d V_{X}\right]}{d t}= & \delta[(1-h) N-L] V_{L X}+n V_{N X} \\
& +\left[f(P h N, L, K)-c-\delta_{K} K\right] V_{K X}-\mu P \log P V_{P X}+\frac{1}{2} \sigma^{2} P^{2} V_{P P X}
\end{aligned}
$$

for $X=L, N, K$ and $P$.

Taking partial derivatives of the first order conditions to obtain the cross-partials of the value function and substituting into the envelope conditions, these conditions can be combined to get a system of four partial differential equations in the policy rules for $c, h, n$ and $V_{P}$ as functions of the state variables $K, L, N$ and $P$.

$$
\begin{aligned}
& \rho+\delta=\delta \frac{f_{2}}{P f_{1}}+\frac{\delta[(1-h) N-L]}{L}\left(\frac{c u^{\prime \prime}}{u^{\prime}} \frac{L c_{L}}{c}+\frac{P h N f_{11}}{f_{1}} \frac{L h_{L}}{h}+\frac{L f_{12}}{f_{1}}\right) \\
& +\frac{n}{N}\left(\frac{c u^{\prime \prime}}{u^{\prime}} \frac{N c_{N}}{c}+\frac{P h N f_{11}}{f_{1}} \frac{N h_{N}}{h}+\frac{P h N f_{11}}{f_{1}}\right) \\
& +\frac{f(P h N, L, K)-c-\delta_{K} K}{K}\left(\frac{c u^{\prime \prime}}{u^{\prime}} \frac{K c_{K}}{c}+\frac{P h N f_{11}}{f_{1}} \frac{K h_{K}}{h}+\frac{K f_{13}}{f_{1}}\right) \\
& -\mu \log P\left(\frac{c u^{\prime \prime}}{u^{\prime}} \frac{P c_{P}}{c}+\frac{P h N f_{11}}{f_{1}} \frac{P h_{P}}{h}+\frac{P h N f_{11}}{f_{1}}+1\right)+\frac{1}{2} \sigma^{2} P^{2} V_{L P P} \\
& \rho \frac{n}{N}=\frac{u^{\prime} P f_{1}-\gamma}{\phi N}+\frac{\delta[(1-h) N-L]}{L} \frac{L n_{L}}{N}+\frac{n}{N} n_{N} \\
& +\frac{f(P h N, L, K)-c-\delta_{K} K}{K} \frac{K n_{K}}{N}-\mu \log P \frac{P n_{P}}{N}+\frac{1}{2} \sigma^{2} P^{2} V_{N P P} \\
& \rho-f_{3}+\delta_{K}=\delta[(1-h) N-L] \frac{c u^{\prime \prime}}{u^{\prime}} \frac{c_{L}}{c}+n \frac{c u^{\prime \prime}}{u^{\prime}} \frac{c_{N}}{c} \\
& +\left[f(P h N, L, K)-c-\delta_{K} K\right] \frac{c u^{\prime \prime}}{u^{\prime}} \frac{c_{K}}{c}-\mu P \log P \frac{c u^{\prime \prime}}{u^{\prime}} \frac{c_{P}}{c}+\frac{1}{2} \sigma^{2} P^{2} V_{K P P} \\
& \rho+\mu(1+\log P)=\frac{u^{\prime} h N f_{1}}{V_{P}}+\sigma^{2} \frac{P V_{P P}}{V_{P}}+\frac{\delta[(1-h) N-L]}{L} \frac{L V_{L P}}{V_{P}}+\frac{n}{N} \frac{N V_{N P}}{V_{P}} \\
& +\frac{f(P h N, L, K)-c-\delta_{K} K}{K} \frac{K V_{K P}}{V_{P}}-\mu \log P \frac{P V_{P P}}{V_{P}}+\frac{1}{2} \sigma^{2} P^{2} V_{P P P}
\end{aligned}
$$

One way to solve for the linearized policy rules, is to linearize these partial differential equations and to substitute linear solutions for the policy rules with undetermined coefficients. Because the equations have to be identically satisfied for all values of the state variables, this gives a (linear) system of 16 equations which can be (numerically) solved for the 16 coefficients of the policy rules. It is simpler however, to use certainty equivalence.

Because in the linearized model the policy rules are linear, $V_{L P P}=V_{N P P}=V_{K P P}=$ $V_{P P P}=0$. Therefore, the terms involving the standard deviation $\sigma$ of the innovations in $\log P$ drop out of first three partial differential equations. The fourth equation determines the policy rule for $V_{P}$ and does depend on $\sigma$. But because the first three equations 
are independent of $V_{P}$, the linearized policy rules for $h, n$ and $c$ do not depend on the degree of uncertainty $\sigma$. In this sense the model is equivalent to a deterministic model with $\sigma=0$. As usual, certainty equivalence arises because of the linearization. Because of certainty equivalence, we can solve for the linearized policy rules of the deterministic model, and use these to simulate the stochastic model.

Using the first order condition to calculate $E\left[d V_{L}\right] / d t=\dot{V}_{L}, E\left[d V_{N}\right] / d t=\dot{V}_{N}$ and $E\left[d V_{K}\right] / d t=\dot{V}_{K}$ and substituting into the envelope conditions, with $\sigma=0$ we get four ordinary differential equations in the jump variables $c, h, n$ and $V_{P}$ as functions of time.

$$
\begin{gathered}
\frac{c u^{\prime \prime}(c)}{u^{\prime}(c)} \frac{\dot{c}}{c}+\frac{\dot{P}}{P}+\frac{P h N f_{11}}{f_{1}}\left(\frac{\dot{P}}{P}+\frac{\dot{h}}{h}+\frac{\dot{N}}{N}\right)+\frac{L f_{12}}{f_{1}} \frac{\dot{L}}{L}+\frac{K f_{13}}{f_{1}} \frac{\dot{K}}{K}=\rho+\delta-\delta \frac{f_{2}}{P f_{1}} \\
\dot{n}=\rho n-\frac{u^{\prime}(c) P f_{1}-\gamma}{\phi} \\
\frac{c u^{\prime \prime}(c)}{u^{\prime}(c)} \frac{\dot{c}}{c}=\rho+\delta_{K}-f_{3} \\
\frac{\dot{V}_{P}}{V_{P}}=\rho+\mu+\mu \log P-\frac{u^{\prime} h N f_{1}}{V_{P}}
\end{gathered}
$$

Combined with the laws of motion for organizational capital (2), employment (22), physical capital (29), and productivity $\dot{P}=-\mu P \log P$ from (31) with $\sigma=0$, these equations form a system of 8 ordinary differential equations in the variables $L, h, N, n$, $K, c, P$ and $V_{P}$.

The steady state is found by setting $\dot{L}=\dot{h}=\dot{N}=\dot{n}=\dot{K}=\dot{c}=\dot{P}=\dot{V}_{P}=0$ and is given by $\bar{L}=(1-\bar{h}) \bar{N}, \bar{n}=0, \bar{P}=1, \bar{c}=f(\bar{P} \bar{h} \bar{N}, \bar{L}, \bar{K})-\delta_{K} \bar{K}$ and

$$
\begin{aligned}
(\rho+\delta) P f_{1}(\bar{P} \bar{h} \bar{N}, \bar{L}, \bar{K}) & =\delta f_{2}(\bar{P} \bar{h} \bar{N}, \bar{L}, \bar{K}) \\
u^{\prime}(\bar{c}) P f_{1}(\bar{P} \bar{h} \bar{N}, \bar{L}, \bar{K}) & =\gamma \\
f_{3}(\bar{P} \bar{h} \bar{N}, \bar{L}, \bar{K}) & =\rho+\delta_{K}
\end{aligned}
$$

Finally, $(\rho+\mu) \bar{V}_{P}=\bar{h} \bar{N} u^{\prime}(\bar{c}) f_{1}(\bar{P} \bar{h} \bar{N}, \bar{L}, \bar{K})$.

The (log)linearized system is of the form $\dot{X}=A X$, with $X=\left[\hat{L}, \hat{h}, \hat{N}, \hat{n}, \hat{K}, \hat{c}, \hat{P}, \hat{V}_{P}^{\prime}\right]^{\prime}$ where a hat over a variable denotes a relative deviation from its (deterministic) steady state, e.g. $\hat{L}=\log (L / \bar{L})$, except for $\hat{n}$, which is hiring as a fraction of steady state employment, $\hat{n}=n / \bar{N}$. The linearized policy rules are given by the stable eigenvectors of the matrix $A$. Given the policy rules, we can simulate the system using the linearized laws of motion for the state variables for any initial value for the state. Because the policy rules nor the laws of motion for the state variables depend on the degree of uncertainty $\sigma$, neither directly nor through $V_{P}$, simulating the linear system for the deterministic model gives impulse responses for the stochastic model for all observable variables because $E[d X]=A X d t$ for all rows except the one for $\hat{V}_{P}$.

\section{References}

[1] Aaronson, Daniel, Ellen R. Rissman and Daniel G. Sullivan (2004). Assessing the jobless recovery. Federal Reserve Bank of Chicago Economic Perspectives, 28(2), pp.2-20. 
[2] Backus, David K., Patrick J. Kehoe and Finn E. Kydland (1995). International Business Cycles: Theory and Evidence. In: Thomas F. Cooley (ed), Frontiers of Business Cycle Research, chapter 11.

[3] Basu, Susanto, John G. Fernald and Miles Kimball (2004). Are Technology Improvements Contractionary? NBER Working Paper No.10592.

[4] Benhabib, Jess, Richard Rogerson and Randall Wright (1991). Homework in Macroeconomics: Household Production and Aggregate Fluctuations. Journal of Political Economy, 99(6), pp.1166-1187.

[5] Bentolila and Bertola (1990). Firing Costs and Labour Demand: How Bad Is Eurosclerosis? Review of Economic Studies, 57(3), pp.381-402.

[6] Blanchard, Olivier and Michael Kremer (1997). Disorganization. Quarterly Journal of Economics, 112(4), pp.1091-1126.

[7] Brynjolfsson, Erik, Lorin M. Hitt and Shinkyu Yang (2002). Intangible Assets: Computers and Organizational Capital. Brookings Papers on Economic Activity, 2002(1), pp.137-181.

[8] Burnside, Craig, Martin Eichenbaum and Sergio Rebelo (1993). Labor Hoarding and the Business Cycle. Journal of Political Economy, 101(2), pp.245-273.

[9] Caballero, Ricardo J., Eduardo M.R.A. Engel and John Haltiwanger (1997). Aggregate Employment Dynamics: Building from Microeconomic Evidence. American Economic Review, 87(1), pp.115-137.

[10] Cho, Jang-Ok and Thomas F. Cooley (1994). Employment and Hours over the Business Cycle. Journal of Economic Dynamics and Control, 18(2), pp.411-432.

[11] Christiano, Lawrence J., Martin Eichenbaum and Robert Vigfusson (2003). What Happens After A Technology Shock? NBER Working Paper No.9819.

[12] Cogley, Timothy and James M. Nason (1995). Output Dynamics in Real-BusinessCycle Models. American Economic Review, 85(3), pp.492-511.

[13] Cole, Harold L. and Richard Rogerson (1999). Can the Mortensen-Pissarides Matching Model Match the Business-Cycle Facts? International Economic Review, 40(4), pp.933-959.

[14] Demers, Michel (1991). Investment under Uncertainty, Irreversibility and the Arrival of Information over Time. Review of Economic Studies, 58(2), pp.333-350.

[15] Francis, Neville and Valerie A. Ramey (2002). Is the Technology-Driven Real Business Cycle Hypothesis Dead? Shocks and Aggregate Fluctuations Revisited. NBER Working Paper No.8726.

[16] Galí, Jordi (1999). Technology, Employment and the Business Cycle: Do Technology Shocks Explain Aggregate Fluctuations. American Economic Review, 89(1), pp.249-271. 
[17] Galí, Jordi and Pau Rabanal (2004). Technology Shocks and Aggregate Fluctuations: How Well Does the RBC Model Fit Postwar U.S. Data? NBER Working Paper No.10636.

[18] Hall, Robert E. (1991). Substitution over Time in Consumption and Work. In: L. McKenzie and S. Zamagni (eds), Value and Capital Fifty Years Later, pp.239-267.

[19] Hall, Robert E. (1995). Lost Jobs. Brookings Papers on Economic Activity, 1995(1), pp.221-256.

[20] Hall, Robert E. (1997). Macroeconomic Fluctuations and the Allocation of Time. Journal of Labor Economics, 15(1), pp.S223-S250.

[21] Hall, Robert E. (1999). Labor-Market Frictions and Employment Fluctuations. In: John B. Taylor and Michael Woodford (eds), Handbook of Macroeconomics, volume 1B, pp.1137-1170.

[22] Hall, Robert E. (2000a). E-Capital: The Link between the Stock Market and the Labor Market in the 1990s. Brookings Papers on Economic Activity, 2000(2), pp.73118.

[23] Hall, Robert E. (2000b). Reorganization. Carnegie-Rochester Conference Series on Public Policy, 52, pp.1-22.

[24] Hall, Robert E. (2003). Wage Determination and Employment Fluctuations. NBER Working Paper No.9967.

[25] Hall, Robert E. (2004). The Labor Market is the Key to Understanding the Business Cycle. mimeo, Stanford University (www.stanford.edu/ $\sim$ rehall).

[26] Hall, Robert E. (2005). Employment Fluctuations and Sticky Wages: Evidence from Flows in the Labor Market. Review of Economics and Statistics, forthcoming.

[27] Hansen, Gary D. (1985). Indivisible Labor and the Business Cycle. Journal of Monetary Economics, 16(3), pp.309-327,

[28] King, Robert G. and Sergio T. Rebelo (1999). Resuscitating Real Business Cycles. In: John B. Taylor and Michael Woodford (eds), Handbook of Macroeconomics, volume 1B, pp.927-1007.

[29] Koenders, Kathryn and Richard Rogerson (2004). Organizational Dynamics Over the Business Cycle: A View on Jobless Recoveries, mimeo, Arizona State University.

[30] Kydland, Finn E. and Edward C. Prescott (1982). Time to Build and Aggregate Fluctuations. Econometrica, 50(6), pp.1345-1370.

[31] Kydland, Finn E. (1995). Business Cycles and Aggregate Labor Market Fluctuations. In: Thomas F. Cooley (ed), Frontiers of Business Cycle Research, chapter 5. 
[32] Millard, Stephen, Andrew Scott and Marianne Sensier (1997). The Labour Market over the Business Cycle: Can Theory Fit the Facts? Oxford Review of Economic Policy, 13(3), pp.70-92.

[33] Mortensen, Dale T. and Christopher A. Pissarides (1994). Job Creation and Job Destruction in the Theory of Unemployment. Review of Economic Studies, 61(3), pp.397-415.

[34] Prescott, Edward C. (1986). Theory Ahead of Business-Cycle Measurement. Federal Reserve Bank of Minneapolis Quarterly Review, 10(4), pp.9-22; Carnegie-Rochester Conference Series on Public Policy, 25, pp.11-44.

[35] Prescott, Edward C. and Michael Visscher (1980). Organization Capital. Journal of Political Economy, 88(3), pp.446-461.

[36] Pries, Michael J. (2004). Persistence of Employment Fluctuations: A Model of Recurring Job Loss. Review of Economic Studies, 71(1), pp.193-215.

[37] Rogerson, Richard (1988). Indivisible Labor, Lotteries, and Equilibrium. Journal of Monetary Economics, 21(1), pp.3-16.

[38] Rotemberg, Julio J. and Michael Woodford (1996). Real-Business-Cycle Models and the Forecastable Movements in Output, Hours, and Consumption. American Economic Review, 86(1), pp.71-89.

[39] Schreft, Stacey L. and Aarti Singh (2003). A Closer Look at Jobless Recoveries. Federal Reserve Bank of Kansas City Economic Review, 88(2), pp.45-73.

[40] Shimer, Robert (2002). Equilibrium Unemployment Fluctuations. mimeo, Princeton University.

[41] Shimer, Robert (2004). The Cyclical Behavior of Equilibrium Unemployment and Vacancies. NBER Working Paper No.9536; forthcoming in the American Economic Review.

[42] Stock, James H. and Mark W. Watson (1999). Business Cycle Fluctuations in U.S. Macroeconomic Time Series. In: John B. Taylor and Michael Woodford (eds), Handbook of Macroeconomics, volume 1A, pp.3-64. 
Table 1. Business cycle statistics: data and model simulations

Panel A. Business cycle statistics

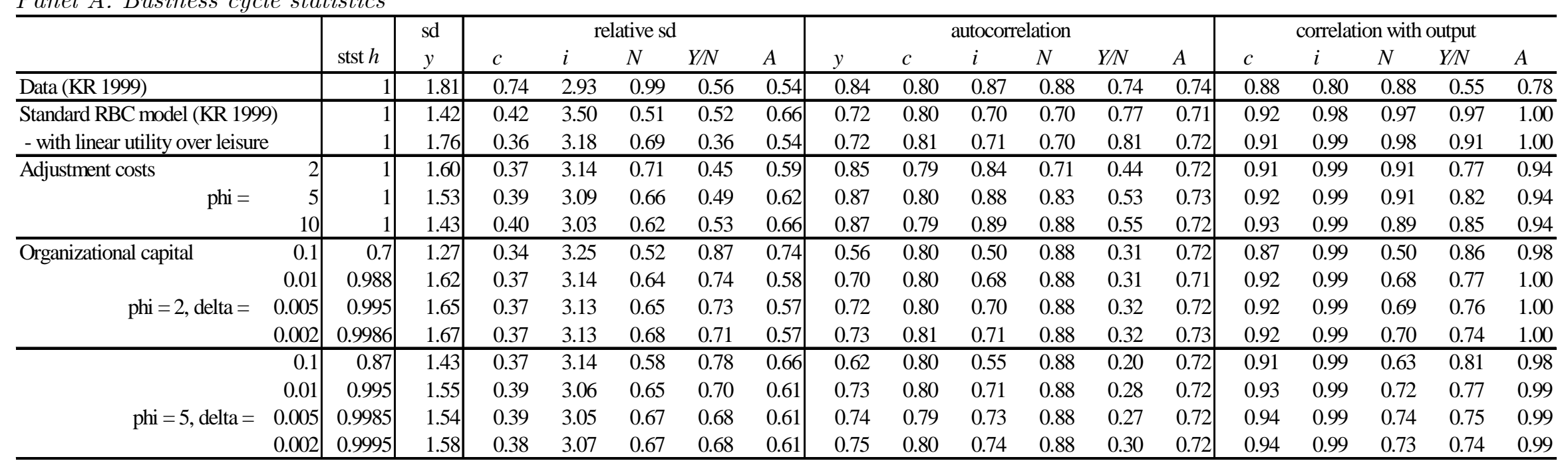

All variables in logaritms. Simulated moments are based on 2,500 years of simulated data (10,000 quarters). Model parameters: $\eta=1$ (logaritmic utility over consumption), $\alpha=1 / 3, \delta_{K}=0.1$ per annum, $\mu=0.021$ and $\sigma=0.0088$ per quarter. For the standard RBC model (second row): $r=6.5 \%$ per annum, $\bar{N}=0.2$ so that $\gamma=4.19$; other rows: $r=4 \%$ per annum, $\bar{N}=0.95$ so that $\gamma=0.92$. All simulations were detrended with the HP filter with smoothing parameter of 1600 . The moments in the first row are calculated from actual data for the US 1953:1-1996-4 and were taken from King and Rebelo (1999). 
Panel B. Employment fluctuations

\begin{tabular}{|c|c|c|c|c|c|c|c|c|c|c|c|c|c|c|c|c|}
\hline & & \multirow[b]{2}{*}{ stst $h$} & \multirow[b]{2}{*}{ rel sd } & \multicolumn{13}{|c|}{ cross-autocorrelations with output at $t+s$, where $s=$} \\
\hline & & & & -6 & -5 & -4 & -3 & -2 & -1 & 0 & 1 & 2 & 3 & 4 & 5 & 6 \\
\hline Data (SW 1999) & & & 0.84 & 0.07 & 0.26 & 0.49 & 0.72 & 0.89 & 0.92 & 0.81 & 0.57 & 0.24 & -0.07 & -0.31 & -0.44 & -0.49 \\
\hline Standard RBC model (KR 199 & & 1 & 0.51 & -0.24 & -0.16 & -0.04 & 0.12 & 0.33 & 0.61 & 0.97 & 0.74 & 0.54 & 0.38 & 0.25 & 0.14 & 0.05 \\
\hline - with linear utility over leisur & & 1 & 0.69 & -0.24 & -0.15 & -0.03 & 0.15 & 0.36 & 0.63 & 0.98 & 0.74 & 0.55 & 0.38 & 0.23 & 0.11 & 0.01 \\
\hline \multirow[t]{3}{*}{ Adjustment costs } & 2 & 1 & 0.71 & -0.23 & -0.12 & 0.05 & 0.27 & 0.55 & 0.89 & 0.91 & 0.68 & 0.47 & 0.29 & 0.14 & 0.02 & -0.07 \\
\hline & 5 & 1 & 0.66 & -0.20 & -0.04 & 0.17 & 0.43 & 0.72 & 0.95 & 0.91 & 0.73 & 0.52 & 0.33 & 0.16 & 0.03 & -0.08 \\
\hline & 10 & 1 & 0.62 & -0.11 & 0.07 & 0.30 & 0.56 & 0.81 & 0.97 & 0.89 & 0.72 & 0.54 & 0.35 & 0.19 & 0.05 & -0.06 \\
\hline \multirow[t]{2}{*}{ Organizational capital } & 0.1 & 0.7 & 0.52 & -0.07 & 0.14 & 0.43 & 0.72 & 0.86 & 0.74 & 0.50 & 0.36 & 0.26 & 0.15 & 0.06 & -0.03 & -0.10 \\
\hline & 0.01 & 0.988 & 0.64 & -0.15 & 0.05 & 0.32 & 0.61 & 0.84 & 0.90 & 0.68 & 0.50 & 0.36 & 0.23 & 0.11 & 0.02 & -0.06 \\
\hline \multirow[t]{2}{*}{ phi $=2$, delta $=$} & 0.005 & 0.995 & 0.65 & -0.16 & 0.06 & 0.33 & 0.62 & 0.85 & 0.90 & 0.69 & 0.51 & 0.36 & 0.22 & 0.11 & 0.01 & -0.08 \\
\hline & 0.002 & 0.9986 & 0.68 & -0.17 & 0.04 & 0.31 & 0.60 & 0.84 & 0.91 & 0.70 & 0.52 & 0.37 & 0.23 & 0.11 & 0.01 & -0.07 \\
\hline \multirow[t]{4}{*}{$(\mathrm{phi}=5)$} & 0.1 & 0.87 & 0.58 & -0.10 & 0.08 & 0.33 & 0.62 & 0.84 & 0.86 & 0.63 & 0.51 & 0.38 & 0.24 & 0.11 & 0.00 & -0.09 \\
\hline & 0.01 & 0.995 & 0.65 & -0.12 & 0.07 & 0.32 & 0.60 & 0.83 & 0.91 & 0.72 & 0.57 & 0.43 & 0.30 & 0.18 & 0.07 & -0.02 \\
\hline & 0.005 & 0.9985 & 0.67 & -0.16 & 0.03 & 0.29 & 0.58 & 0.83 & 0.92 & 0.74 & 0.59 & 0.44 & 0.29 & 0.15 & 0.03 & -0.07 \\
\hline & 0.002 & 0.9995 & 0.67 & -0.16 & 0.05 & 0.31 & 0.59 & 0.83 & 0.92 & 0.73 & 0.58 & 0.42 & 0.27 & 0.13 & 0.01 & -0.09 \\
\hline
\end{tabular}

The moments in the first row are calculated from actual data for the US 1953:1-1996-4 and were taken from Stock and Watson (1999), who detrended the data with a bandpass filter that passes cyclical fluctuations with periodicities between 6 quarters and 8 years. Other notes: see under panel A. 
Table 2. Model simulations for different values of $\phi$ and $\delta$

Panel A. Value for $h^{*}$ such that $n=0$ immediately after shock

\begin{tabular}{r|rrrrrrrr}
\hline \multirow{2}{*}{ delta $=$} & \multicolumn{7}{|c}{ adjustment costs, phi } \\
\hline 0.1 & 0.1 & 0.2 & 0.5 & 1 & 2 & 5 & 10 & 20 \\
\hline 0.05 & 0.959 & 0.908 & 0.871 & 0.833 & 0.783 & 0.695 & 0.610 & 0.505 \\
0.02 & 0.979 & 0.974 & 0.927 & 0.908 & 0.883 & 0.840 & 0.800 & 0.751 \\
0.01 & 0.988 & 0.985 & 0.980 & 0.957 & 0.946 & 0.929 & 0.913 & 0.894 \\
0.005 & 0.993 & 0.992 & 0.989 & 0.986 & 0.970 & 0.961 & 0.953 & 0.944 \\
0.002 & 0.997 & 0.996 & 0.995 & 0.994 & 0.993 & 0.979 & 0.975 & 0.970 \\
0.001 & 0.998 & 0.998 & 0.997 & 0.997 & 0.996 & 0.993 & 0.989 & 0.987 \\
\hline
\end{tabular}

Panel B. Time at which hiring is highest (in months)

\begin{tabular}{r|rrrrrrrr}
\hline delta $=$ & \multicolumn{7}{c}{ adjustment costs, phi } \\
\hline 0.1 & 0.1 & 0.2 & 0.5 & 1 & 2 & 5 & 10 & 20 \\
\hline 05 & 1 & 2 & 2 & 3 & 3 & 4 & 6 & 6 \\
0.02 & 2 & 2 & 3 & 3 & 4 & 6 & 7 & 8 \\
0.01 & 2 & 3 & 3 & 4 & 5 & 7 & 8 & 10 \\
0.005 & 2 & 3 & 4 & 5 & 6 & 8 & 10 & 12 \\
0.002 & 3 & 4 & 5 & 6 & 7 & 9 & 11 & 13 \\
0.001 & 3 & 4 & 5 & 6 & 8 & 10 & 12 & 15 \\
\hline
\end{tabular}

Panel C. Peakvalue of hiring (times $10^{-3}$ per month)

\begin{tabular}{r|rrrrrrrr}
\hline & \multicolumn{8}{|c}{ adjustment costs, phi $=$} \\
delta $=$ & 0.1 & 0.2 & 0.5 & 1 & 2 & 5 & 10 & 20 \\
\hline 0.1 & 1.64 & 1.23 & 0.82 & 0.59 & 0.41 & 0.24 & 0.15 & 0.08 \\
0.05 & 1.37 & 1.04 & 0.71 & 0.52 & 0.38 & 0.24 & 0.16 & 0.11 \\
0.02 & 1.06 & 0.81 & 0.56 & 0.42 & 0.31 & 0.20 & 0.14 & 0.10 \\
0.01 & 0.88 & 0.67 & 0.46 & 0.35 & 0.26 & 0.17 & 0.12 & 0.08 \\
0.005 & 0.75 & 0.57 & 0.39 & 0.29 & 0.22 & 0.14 & 0.10 & 0.07 \\
0.002 & 0.64 & 0.48 & 0.33 & 0.25 & 0.18 & 0.12 & 0.08 & 0.06 \\
0.001 & 0.59 & 0.45 & 0.31 & 0.23 & 0.17 & 0.11 & 0.08 & 0.05 \\
\hline
\end{tabular}

Values for $h^{*}$ in panel A of the table. Other parameters: $\alpha=1 / 3, \delta_{K}=10 \%$ per annum, $r=4 \%$ per annum, $\bar{N}=0.95, \theta=1-\alpha$ (additively separable production function). For all simulations presented, $n=0$ immediately after the increase in productivity. 

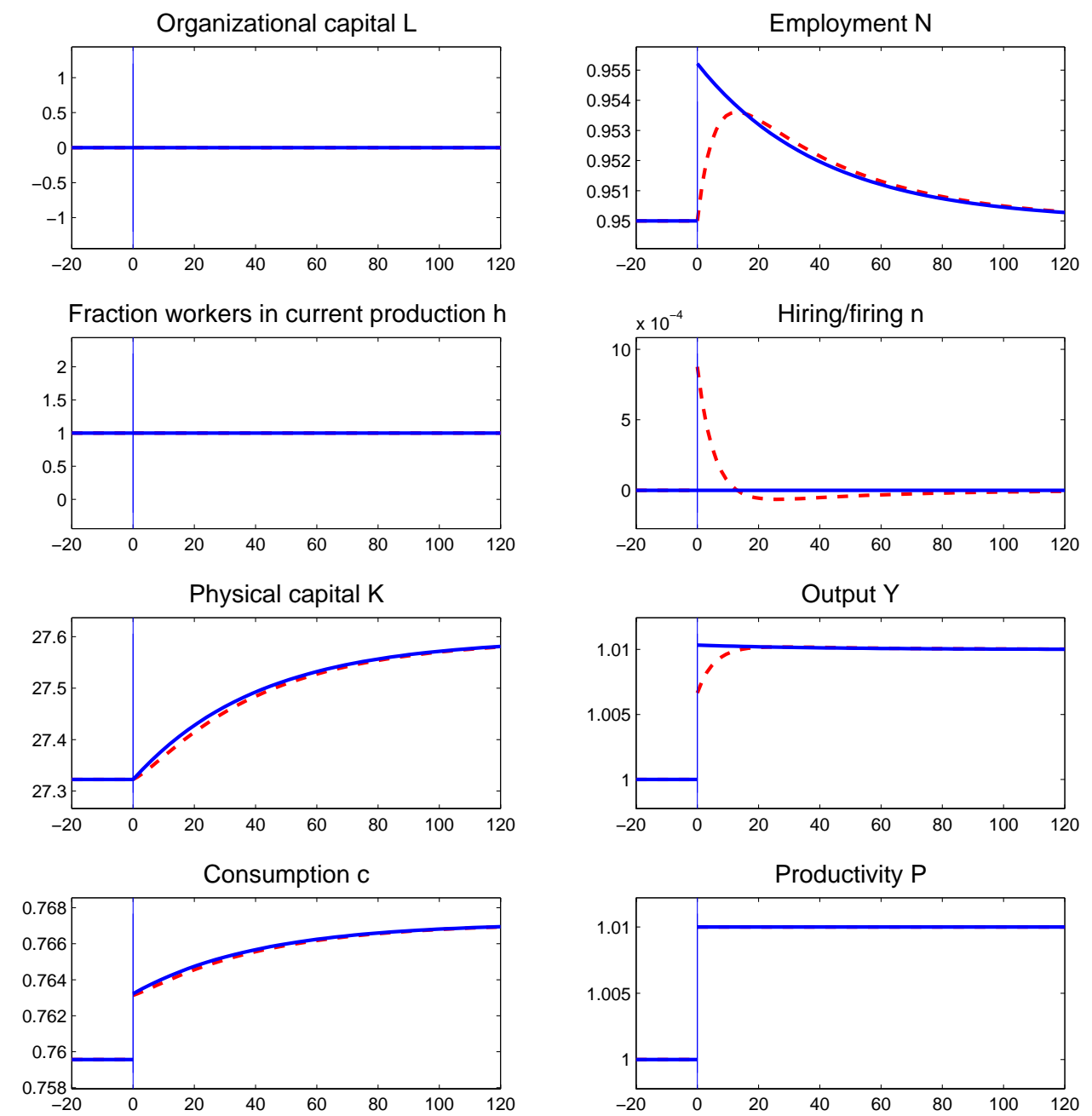

Figure 3: Impulse responses to a $1 \%$ permanent increase in productivity in a standard RBC model (solid lines) and an RBC model with convex adjustment costs in employment (dashed lines). Time on horizontal axis in months. Model parameters: $\alpha=1 / 3, \delta_{K}=$ $10 \%$ per annum, $r=4 \%$ per annum, $\bar{N}=0.95$, TFP normalized such that $\bar{Y}=1$, $\theta=1-\alpha$ (additively separable production function), $\phi=0$ and 10 . 

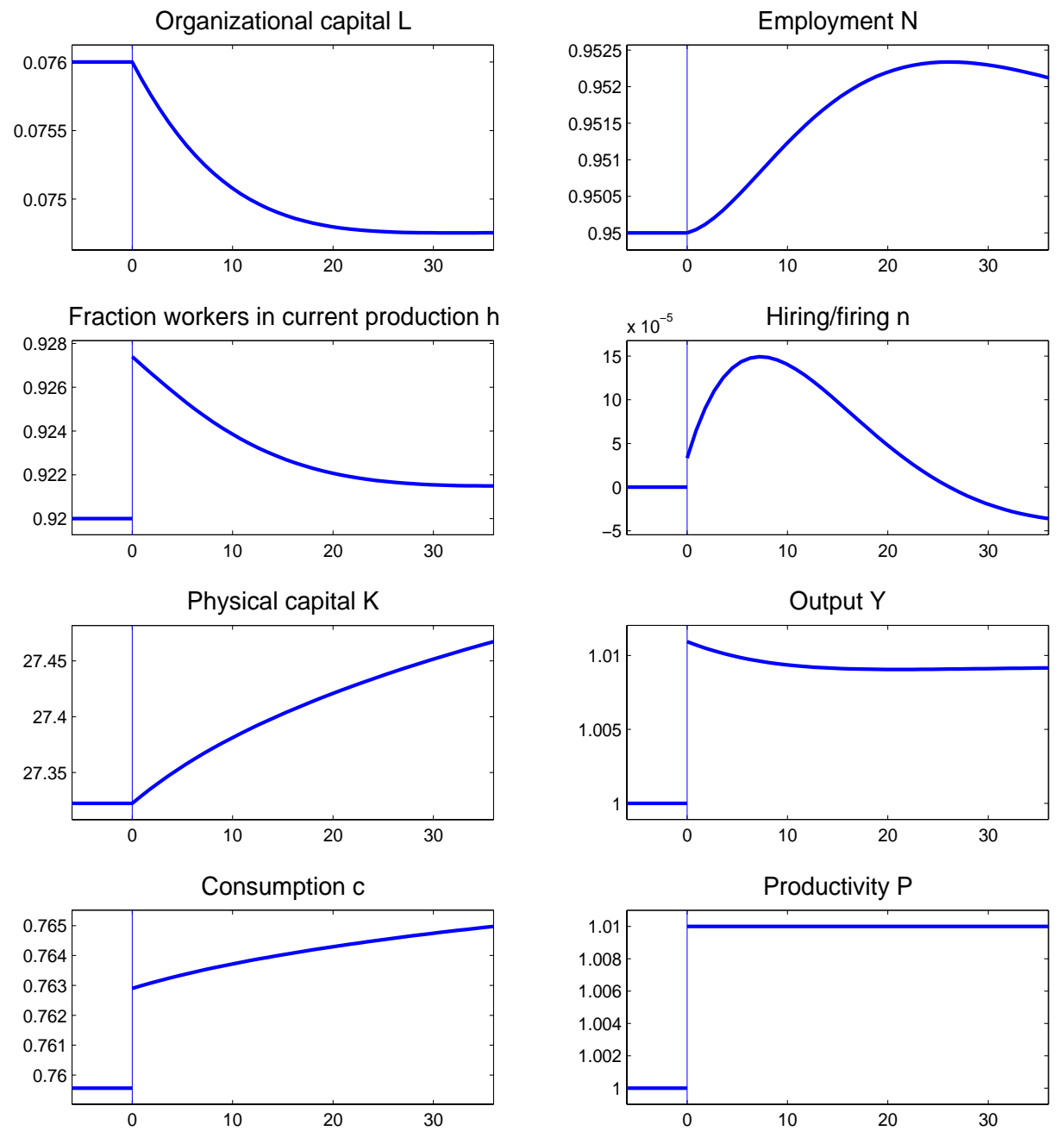

Figure 4: Impulse responses to a $1 \%$ permanent increase in productivity in an RBC model extended with convex adjustment costs in employment and organizational capital. Time on horizontal axis in months. Model parameters: $\alpha=1 / 3, \delta_{K}=10 \%$ per annum, $r=4 \%$ per annum, $\bar{N}=0.95$, TFP normalized such that $\bar{Y}=1, \theta=1-\alpha$ (additively separable production function), $\phi=10, \bar{h}=0.92$ and $\delta=0.02$. 

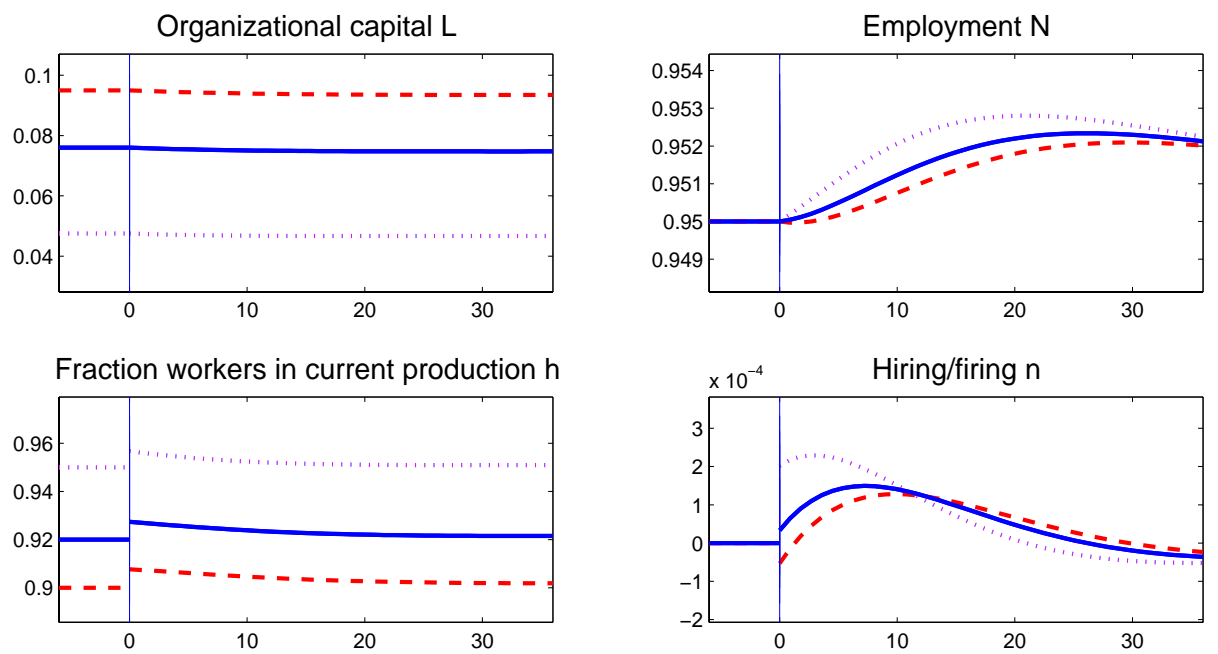

Physical capital K

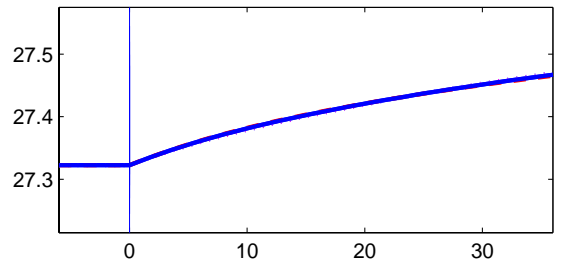

Output $Y$

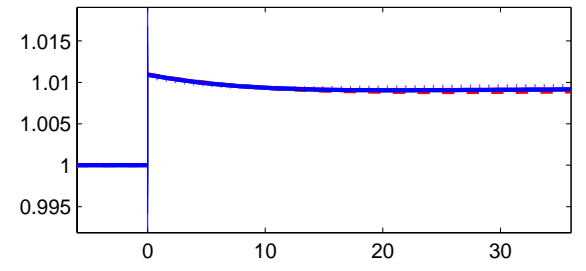

Consumption c
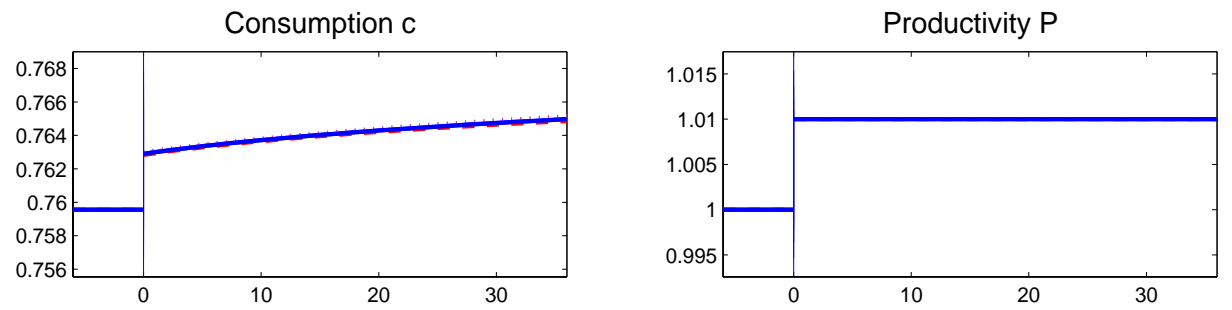

Figure 5: Impulse responses to a $1 \%$ permanent increase in productivity in an RBC model extended with convex adjustment costs in employment and organizational capital, for different values of the share of organizational capital in production. Time on horizontal axis in months. Model parameters: $\alpha=1 / 3, \delta_{K}=10 \%$ per annum, $r=4 \%$ per annum, $\bar{N}=0.95$, TFP normalized such that $\bar{Y}=1, \theta=1-\alpha$ (additively separable production function), $\phi=10, \delta=0.02$ and $\bar{h}=0.9$ (dashed), 0.92 (solid) and 0.95 (dotted). 

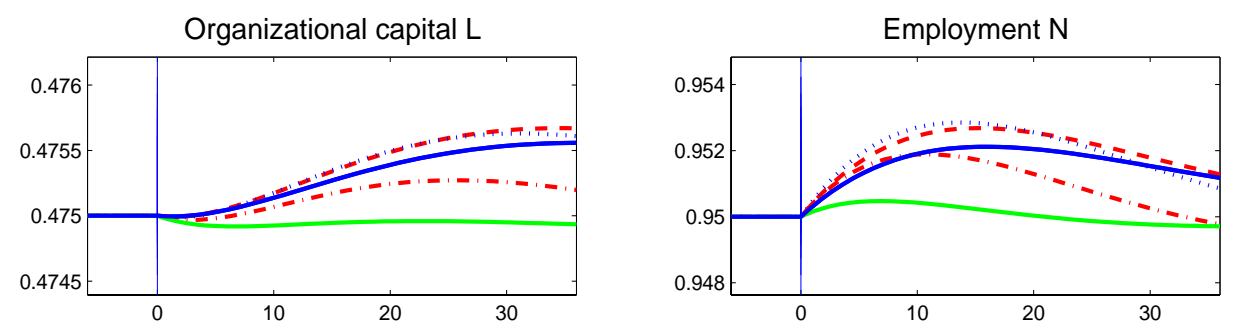

Fraction workers in current production $\mathrm{h}$
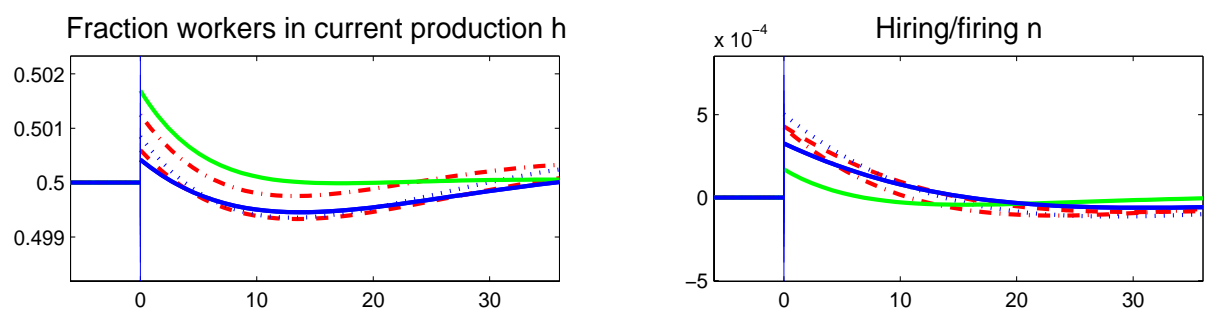

Output $Y$
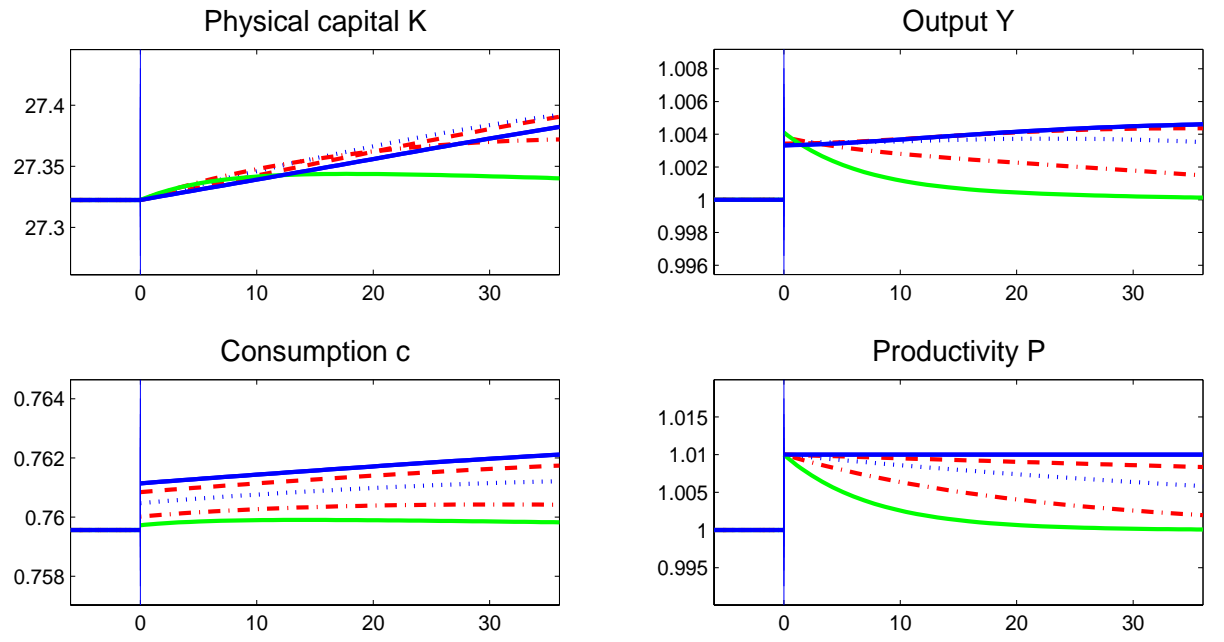

Figure 6: Impulse responses to a 1\% increase in productivity in an RBC model extended with convex adjustment costs in employment and organizational capital, for different values of the persistence parameter for productivity $\mu$. Time on horizontal axis in months. Model parameters: $\alpha=1 / 3, \delta_{K}=10 \%$ per annum, $r=4 \%$ per annum, $\bar{N}=0.95$, TFP normalized such that $\bar{Y}=1, \theta=0$ (Cobb-Douglas production function), $\phi=10, \bar{h}=0.5, \delta=0.02$ and $\mu=0$ (dark solid), 0.015 (dashed), 0.045 (dotted), 0.135 (dash-dot) and 0.4 (light solid) per quarter. 